\title{
Evaluating the Consistency of a Breathing Flow Recording Device Across Different Elastomeric Half-Mask Respirators
}

\author{
Samuel Jennings Munnis \\ West Virginia University, sjmunnis@mix.wvu.edu
}

Follow this and additional works at: https://researchrepository.wvu.edu/etd

Part of the Occupational Health and Industrial Hygiene Commons

\section{Recommended Citation}

Munnis, Samuel Jennings, "Evaluating the Consistency of a Breathing Flow Recording Device Across Different Elastomeric Half-Mask Respirators" (2019). Graduate Theses, Dissertations, and Problem Reports. 7431.

https://researchrepository.wvu.edu/etd/7431

This Thesis is protected by copyright and/or related rights. It has been brought to you by the The Research Repository @WVU with permission from the rights-holder(s). You are free to use this Thesis in any way that is permitted by the copyright and related rights legislation that applies to your use. For other uses you must obtain permission from the rights-holder(s) directly, unless additional rights are indicated by a Creative Commons license in the record and/ or on the work itself. This Thesis has been accepted for inclusion in WVU Graduate Theses, Dissertations, and Problem Reports collection by an authorized administrator of The Research Repository @ WVU. For more information, please contact researchrepository@mail.wvu.edu. 
Evaluating the Consistency of a Breathing Flow Recording Device Across Different Elastomeric Half-Mask Respirators

Samuel Jennings Munnis

Follow this and additional works at: https://researchrepository.wvu.edu/etd

Part of the Occupational Health and Industrial Hygiene Commons 


\title{
Evaluating the Consistency of a Breathing Flow Recording Device Across Different Elastomeric Half-Mask Respirators
}

\author{
Samuel J. Munnis \\ Thesis submitted \\ to the Benjamin M. Statler \\ College of Engineering and Mineral Resources \\ at West Virginia University \\ in partial fulfillment of the requirements for the degree of \\ Master of Science in \\ Industrial Hygiene \& Safety
}
Xinjian He, Ph.D., Chair
Eun Gyung Lee, Ph.D.
Gary Winn, Ph. D.

Department of Industrial and Management Systems Engineering

Morgantown, West Virginia

2019

Keywords: elastomeric respirator, healthcare worker, minute volume, respiratory flow, PAPR Copyright 2019 Samuel J. Munnis 


\title{
Abstract \\ Evaluating the Consistency of a Breathing Flow Recording Device Across Different Elastomeric Half-Mask Respirators
}

\author{
Samuel J. Munnis
}

The National Institute of Occupational Safety and Health (NIOSH) is the organization in charge of approving respiratory devices in the United States, as permitted by 42 CFR Part 84. Standards that NIOSH uses to certify powered air-purifying respirators (PAPRs) are based on respiratory data collected before the $21^{\text {st }}$ century. With new technologies, it is possible to gain a more accurate understanding of breathing flow of healthcare workers (HCWs). A new portable breathing flow recording device developed by The S.E.A. Group was intended for use with a Sundström SR100 mask with a P100 filter. This study tests the device with a North 7700 mask with a P100 filter as well to evaluate the device's consistency of measurement among other types of elastomeric half-mask respirators (EHMRs). The respirators are first calibrated for use with the device, then each is exposed to four different measurement conditions. Each condition is tested at varying flow rates from 5 liters per minute to 75 liters per minute. The results are analyzed using a two-sided hypothesis test of difference in independent population means, with a null hypothesis ( $\left.\mathrm{H}_{0}\right)$ being: $\mathrm{H}_{0}=\mu_{1}-\mu_{2}=0$. A two-tailed t-test is performed, assuming equal variances. The results show that the hypothesis is accepted $(\mathrm{p}>0.05)$, therefore the results obtained by the device are not significantly different. These results suggest the device can potentially be used to measure the breathing flow rate of HCWs using various types of EHMRs. With the consistency and reliability of new devices in measuring breathing flow of HCWs in a real-time work environment, new data can be gathered to supplant the outdated information used to shape current NIOSH respirator certification standards. 


\section{Table of Contents}



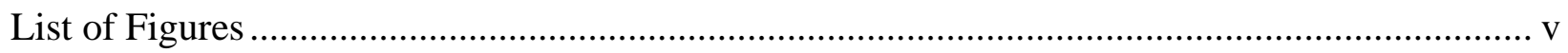

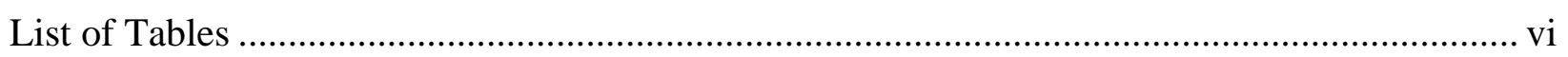

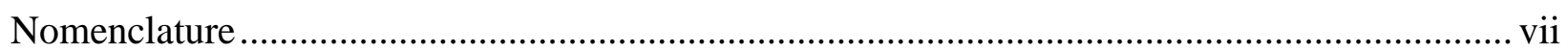

Abbreviations ………………………........................................................................ vii

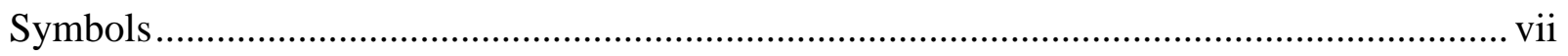

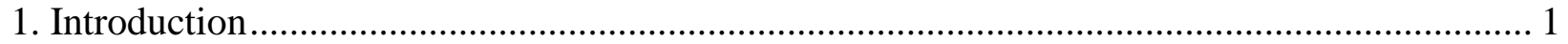

1.1 The Elastomeric Half-Mask Respirator............................................................................ 1

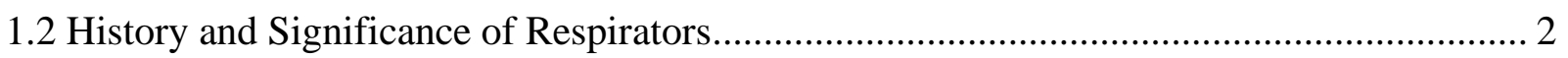

1.3 New Developments Involving PAPR Standards .............................................................. 3

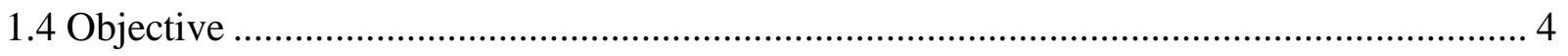

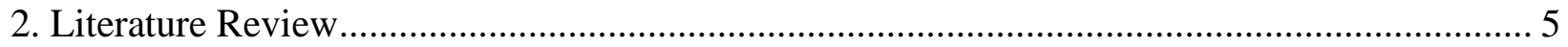

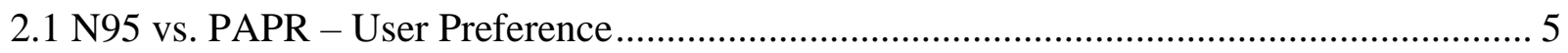

2.2 N95 vs. PAPR - Emergency Readiness .................................................................. 5

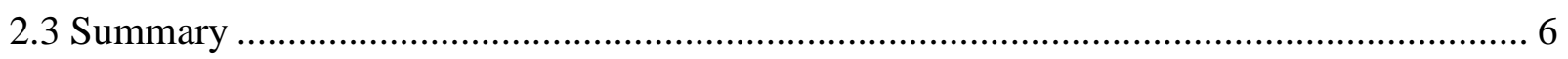

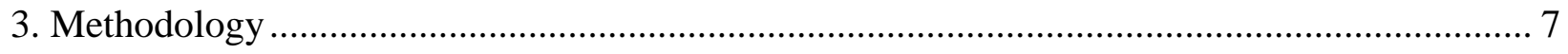

3.1 Overview of the Evaluation Process …………………................................................ 7

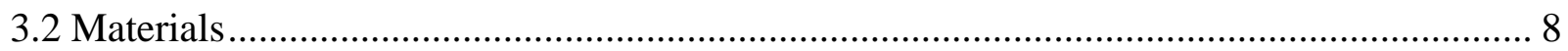

3.2.1 The S.E.A. Group Pressure Data Logger..................................................................... 8

3.2.2 Sundström SR100 EHMR with P100 Filter Cartridge ……………............................ 10

3.2.3 North 7700 Series EHMR with P100 Filter Cartridges .............................................. 10

3.2.4 TSI 4000 Series High Performance Linear OEM Mass Flowmeter .............................. 11

3.2.5 Airflow PVM100 Micromanometer .................................................................... 11

3.2.6 Hans Rudolph Series 1101 Breathing Simulator ....................................................... 12

3.3 Filter Characterization Method ................................................................................ 12

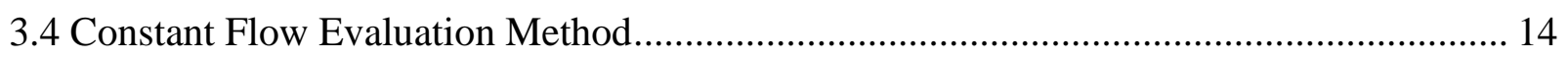

3.5 Simulated Breathing Evaluation Method ..................................................................... 15



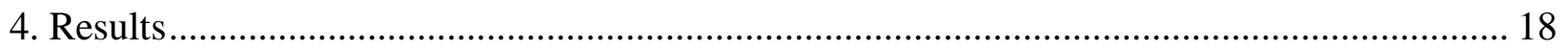

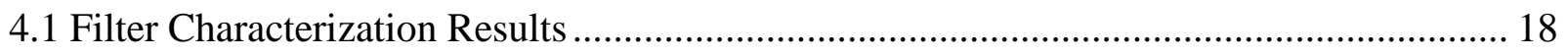

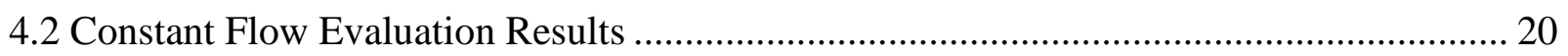




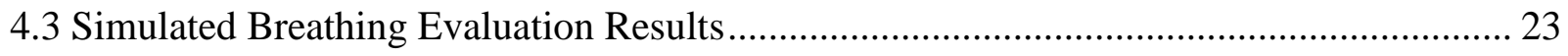

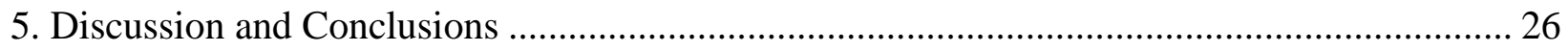

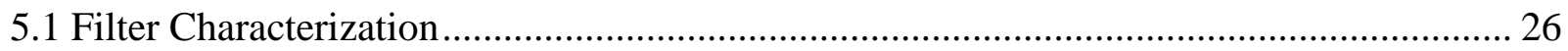

5.2 PDL Consistency and Accuracy Across Different Respirators ..................................... 26

5.3 PDL Consistency and Accuracy Across Different Seal Conditions .............................. 27

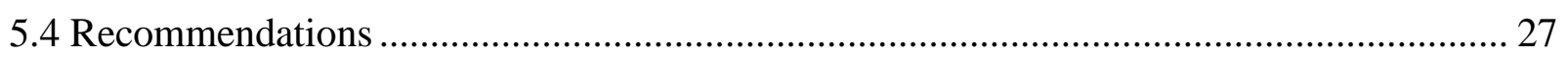

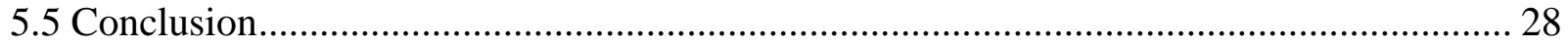

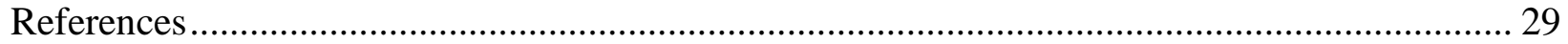

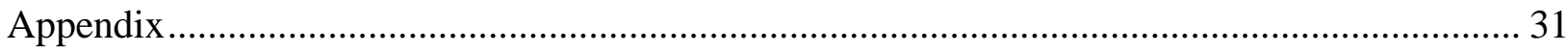

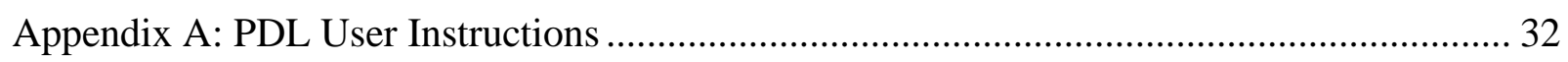

Appendix B: PDL Software Printouts ........................................................................... 51 


\section{List of Figures}

Figure 1.1: Diagrams of typical respirators [1] ................................................................... 1

Figure 3.1: S.E.A. Pressure Data Logger Unit...................................................................... 8

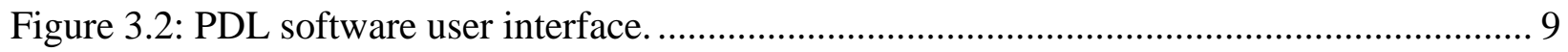

Figure 3.3: PDL connection adapters for Sundström (pictured left) and North (pictured right)



Figure 3.4: Sundström SR100 Respirator ........................................................................... 10



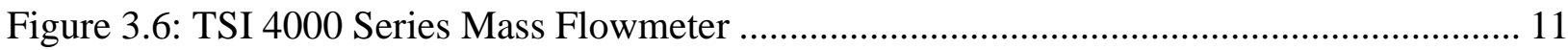

Figure 3.7: Airflow PVM100 Micromanometer.................................................................. 12

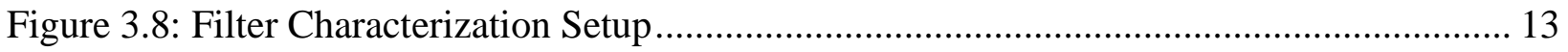

Figure 3.9: Sundström (left) and North (right) constant flow evaluation setup........................... 14

Figure 3.10: Leaks introduced to Sundström (left) and North (right) respirators.......................... 15

Figure 4.1: Sundström SR100 filter characteristic curve ............................................................ 19

Figure 4.2: North 7700 Series filter characteristic curve ............................................................ 19 


\section{List of Tables}

Table 3.1: Lung and breathing effort parameters............................................................... 16

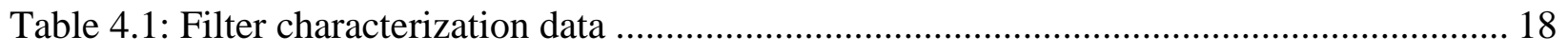



Table 4.3: Sealed, constant flow statistical analysis results.............................................. 21

Table 4.4: Leaking, constant flow MV averages ......................................................... 21

Table 4.5: Leaking, constant flow statistical analysis results ............................................. 22

Table 4.6: Sealed, simulated breathing MV averages........................................................ 23

Table 4.7: Sealed, simulated breathing statistical analysis results......................................... 24

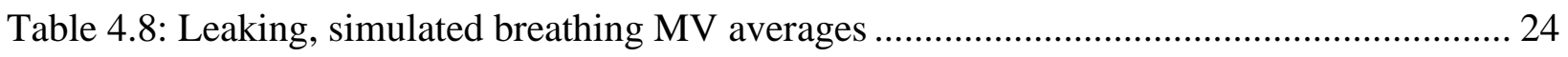

Table 4.9: Leaking, simulated breathing statistical analysis results ...................................... 25 


\section{Nomenclature}

\section{Abbreviations}

$\begin{array}{cc}\text { BrPM } & \text { Breaths per minute } \\ \text { EHMR } & \text { Elastomeric half-mask respirator } \\ \text { FFR } & \text { Filtering facepiece respirator } \\ \text { HCW } & \text { Healthcare worker } \\ \text { MV } & \text { Minute volume } \\ \text { NIOSH } & \text { National Institute of Occupational Safety and Health } \\ \text { NPPTL } & \text { National Personal Protective Technology Laboratory } \\ \text { OSHA } & \text { Occupational Safety and Health Administration } \\ \text { OSHRC } & \text { Occupational Safety and Health Review Commission } \\ \text { PAPR } & \text { Powered air-purifying respirator } \\ \text { PDL } & \text { Pressure data logger } \\ \text { PIF } & \text { Peak inspiratory flow } \\ \text { RPE } & \text { Respiratory protective equipment } \\ \text { RR } & \text { Respiratory rate } \\ \text { USBM } & \text { United States Bureau of Mines } \\ \text { TV } & \text { Tidal volume }\end{array}$

\section{Symbols}

$\begin{array}{cc}\mathrm{H}_{\mathrm{A}} & \text { Alternative hypothesis } \\ \mathrm{H}_{0} & \text { Null hypothesis } \\ \mathrm{N}_{\mathrm{i}} & \text { Number of observations } \\ \mathrm{S}_{\mathrm{p}} & \text { Pooled variation } \\ \mathrm{T} & \text { Test statistic } \\ \mathrm{T}_{\text {crit }} & \text { Critical value } \\ \mathrm{X}_{\mathrm{i}} & \text { Sample mean }\end{array}$


Population mean 


\section{Introduction}

\subsection{The Elastomeric Half-Mask Respirator}

Elastomeric half-mask respirator (EHMR) is just one of many types of respiratory protective equipment (RPE). They are commonly used in industries where protection from harmful airborne particulates is necessary, such as: painting, detail work, and healthcare. They typically consist of a silicone or similar material covering the nose and mouth that is secured tightly to the head using elastic straps. This silicone mask has inhalation valves that are preceded by airpurifying elements. These can be in the form of a disposable filter, a reusable cartridge, or a cannister. There are many types of filters that can be used, with each being designed for specific hazards. Figure 1 shows examples of typical quarter mask, half mask, and full facepiece respirators.

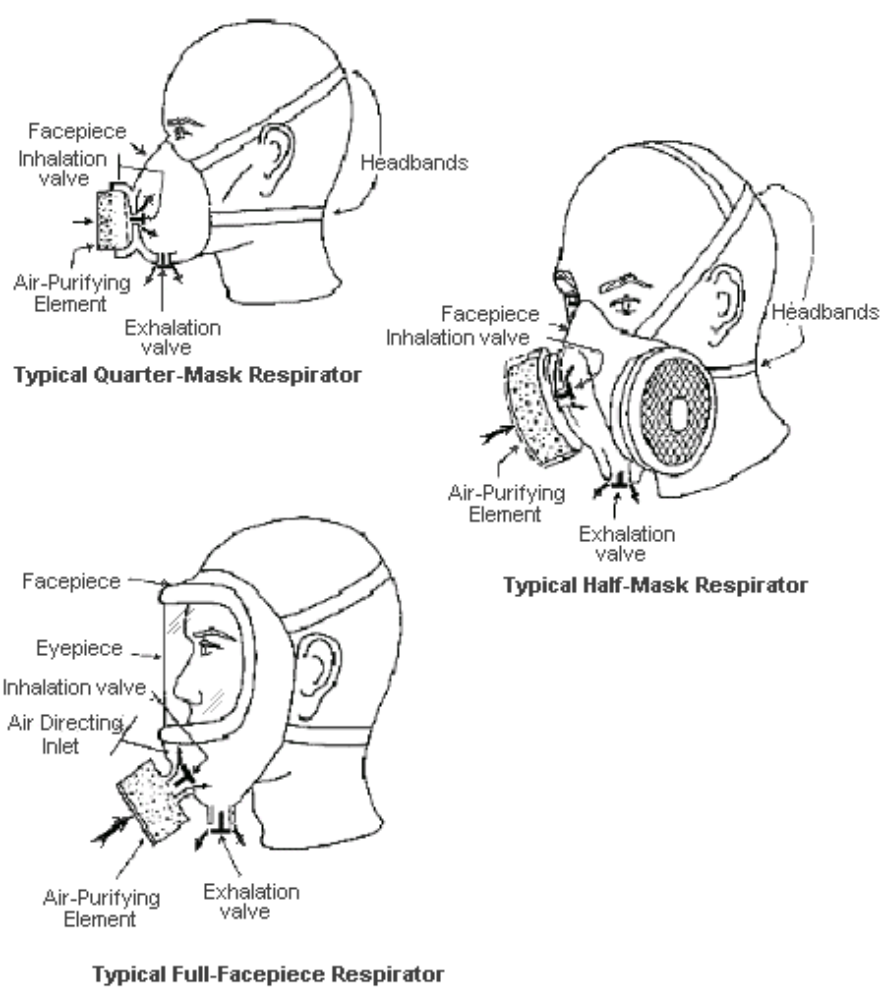

Figure 1.1: Diagrams of typical respirators [1] 


\subsection{History and Significance of Respirators}

Respiratory protection has been around for centuries in many different forms. Animal bladders, herbs, wet cloths, sponges and several other methods were implemented over the years. It wasn't until the $18^{\text {th }}$ and $19^{\text {th }}$ century that respirators began to resemble modern systems. This came with the discovery of Brownian motion in the early 1800s. With a more precise understanding of the behavior of particles suspended in air, it was possible to develop more effective methods of filtration. However, these technologies would not be implemented on a large scale until the $20^{\text {th }}$ century [2].

The United States Bureau of Mines (USBM) started a certification program for respirators, which was the first of its kind. The USBM went on to help the United States in both World War I and World War II, supplying the armed forces with respiratory technology that protect troops. The USBM would continue to progress its regulations through the mid-20 $0^{\text {th }}$ century [2]. The Occupational Safety and Health Administration (OSHA) was established in the early 1970s as a response to nationwide demand for workplace safety reform. The Occupational Safety and Health Act, signed into law in 1970, led to the creation of OSHA, the National Institute for Occupational Safety and Health (NIOSH), and the Occupational Safety and Health Review Commission (OSHRC) [3]. OSHA effectively replaced USBM as the organization in charge of workplace safety within the United States.

Among many other regulations, OSHA implemented 29 CFR 1910.134. This is known as the Respiratory Protection Standard. The standard holds employers accountable for ensuring proper respiratory protection in the workplace. According to the standard: "Respirators are required when "effective engineering controls are not feasible, or while they are being instituted. [4]"' The standard also sets forth the methods with which to choose proper respiratory protection, along with how to ensure their proper use. 


\subsection{New Developments Involving PAPR Standards}

In recent years, NIOSH has been pushing to update respiratory protection that is available for HCWs [5]. Primarily, they are seeking new designs for PAPRs that are more comfortable, user friendly, and just as effective or perhaps even more effective at providing safety. This push comes as a response to frequent outbreaks of contagious pathogens in the $21^{\text {st }}$ century. H1N1, SARS, Ebola, and other deadly diseases have tested the healthcare industry [6]. With highly contagious threats such as these, it is imperative that HCWs have as sophisticated respiratory protection as possible to protect their health and help prevent the propagation of disease. Currently, the most commonly used mask in healthcare is the N95 filtering facepiece respirator (FFR) [7]. Although this mask is highly effective at protecting HCWs, PAPRs are given much higher assigned protection factors (APFs) and therefore are a superior alternative when considering the safety of HCWs [4].

The demand for improved PAPR designs elicits a second look at current NIOSH PAPR certification standards. As covered in of 42 CFR Part 84, minimum operational flows of PAPRs are $115 \mathrm{~L} / \mathrm{min}$ for tight-fitting PAPRs and $170 \mathrm{~L} / \mathrm{min}$ for loose-fitting PAPRs. The purpose of this standard is to ensure that the PAPR has sufficient airflow to create positive pressure within the mask. This positive pressure prevents inward leakage of contaminants, as air is forced to the atmosphere, where pressure is lower. The main consideration for this standard is worker breathing flow. As the worker breathes, they either create an increase (during exhalation) or decrease (during inhalation) of pressure within the mask. If worker inhalation flow exceeds the supplied air flow, positive pressure is compromised, and inward leakage of contaminants can occur for loose-fitting PAPRs. The data used as a basis for these standards was collected 50 years ago, on industrial workers [8].

To generate new designs for PAPRs that are more user friendly and cost effective, NIOSH could consider the possibility of new standards for lower flow rate PAPRs. HCWs are often not exposed to labor intensive working conditions. With the lower respiratory flow rates that are common in healthcare work [9], there is an opportunity for alternative standards that allow lower air supply flows. The equipment built around these standards could be lighter, quieter, and cheaper 
than equipment that is currently required. Correcting these issues could make PAPRs more commonly accepted and advantageous compared to N95 respirators [10].

\subsection{Objective}

The purpose of this study is to investigate the performance of a device that can be used in accurately monitoring breathing flow of HCWs as they perform work that requires respirators. The device, a pressure data logger (PDL) developed by The S.E.A. Group, will be subjected to four different airflow conditions with varying flow rates. This will be done as the device is attached to the original manufacturer's EHMR, a Sundström SR100, and a similar mask from a competitor, a North 7700 series. Both masks are equipped with P100 filter cartridges, but the masks differ in

shape and filter positioning. The results of this study will provide more insight on the overall consistency and capability for this PDL, and how it can be incorporated in creating a better understanding of the breathing flow of HCWs in a work environment. 


\section{Literature Review}

\subsection{N95 vs. PAPR - User Preference}

N95 respirators are the most commonly used RPE in healthcare [7]. However, these masks have been reported to give HCWs discomfort. The results of a survey performed by Baig et al. in 2010 shows that N95s are far from ideal in terms of user comfort [11]. Common issues mentioned were the masks' interference with breathing, heat buildup, and interference with facial hair. PAPRs, while not as commonly used due to their high cost and maintenance [12], have the potential to meet HCWs demands. Their design allows use with facial hair and has a breathing space that is not granted by N95s. The restrictive nature of N95 masks causes breathing difficulty, and the resulting decrease in oxygen consumption is even believed to cause headaches during prolonged use in a healthcare environment [13]. The constant circulation of fresh air provided by a PAPR prevents this, and also helps to alleviate thermal stress caused by the heat of exhaled air [12].

The main issue preventing prevalence of PAPRs is their cost [12]. Hospitals generally are not able to sacrifice enough of their budget on providing PAPRs for all departments, and it is difficult for PAPRs to be used across multiple departments simultaneously. Another common complaint is that PAPRs can be easily run low on battery. Dedicated charging stations have been suggested as a way of making sure they are not misplaced and keeping them charged when needed for use. Many of these issues in healthcare could potentially be addressed with the development of lower flow rate PAPRs.

\subsection{N95 vs. PAPR - Emergency Readiness}

Since the turn of the $21^{\text {st }}$ century there have been many public health epidemics that have tested the emergency readiness of healthcare systems. N95s and PAPRs have been used during epidemics involving H1N1, SARS, Ebola, and TB. During these emergencies, the respiratory protection of HCWs is vital for their safety and for the prevention of spreading disease. Given their higher assigned protection factors (APFs), PAPRs are certified by NIOSH to be more effective at protecting the user than N95s [4]. Additionally, PAPRs have been found favorable to HCWs in 
high risk scenarios. This is because the devices are reusable and give the user a better sense of protection [14]. A study performed by Khoo et al. observed worker perceptions of N95s and PAPRs during a SARS outbreak. The results showed that a majority of the HCWs involved preferred to use PAPRs. While they did recognize greater difficulty in communication, they were pleased with the protection and ability to perform tasks while wearing the device [10].

In 2008, Roberge et al. had an article published in the American Journal of Infection Control that entertained the possibility of using N95s concurrently with PAPRs during high-risk scenarios [15]. They concluded that, although this seems rational in increasing APF, there is little advantage evident in doing this. The slight amount of added protection is expected to be outweighed by the hindrance of wearing both devices.

The Safety and Health Magazine featured an article in the summer of 2019 that discussed NIOSH's interest in pursuing new design possibilities for PAPRs in healthcare [5]. The article indicates that the National Personal Protective Technology Laboratory (NPPTL) is gathering a consensus of recommendations for PAPR design. NIOSH states that a key motivation for this is the amount of public health emergencies over the course of the $21^{\text {st }}$ century. This suggests that NIOSH recognizes the potential of PAPRs in healthcare and is trying it's best to try to adapt them so that more HCWs are properly protected and capable of performing during epidemics.

\subsection{Summary}

In summary, there are numerous advantages and disadvantages provided by PAPRs with respect to user experience. PAPRs are costly, more complex, and louder. However, they provide superior protection and breathing comfort compared to N95s. During public health emergencies, HCWs seem to prefer PAPRs to N95s due to reusability, protection, comfort, and worker performance. Prospective developments in PAPR technology could lead to devices that preserve their current advantages and minimize their disadvantages. It is important for us to fully understand the characteristics of HCW's breathing as they perform their job. Doing so will provide a basis on which to generate new PAPR standards and technologies that are necessary to improve protection, performance, and comfort of healthcare workers. 


\section{Methodology}

\subsection{Overview of the Evaluation Process}

The evaluation process begins with filter characterization of each EHMR and filter cartridges to ensure accuracy of the PDL. The respirators are subjected to flow rates ranging from $0 \mathrm{~L} / \mathrm{min}$ to $80 \mathrm{~L} / \mathrm{min}$. The pressure inside the mask is displayed on a micromanometer and recorded. A $2^{\text {nd }}$ order polynomial "calibration curve" is generated using the results. The coefficients of this curve are necessary to properly display the PDL's recorded data using its accompanying software.

Once the coefficients of the calibration curve are known, each mask is connected to the PDL with an adapter and exposed to four airflow conditions. The first two conditions involve constant airflows of $10 \mathrm{~L} / \mathrm{min}$ to $75 \mathrm{~L} / \mathrm{min}$. In the first condition, the respirator is close to perfectly sealed. In the second, a leak is introduced. The masks are then setup in connection to a breathing simulator. Various breathing parameters are input to expose each mask to similar breathing conditions. Respiratory rate is varied from 15 breaths per minute (BrPM) to $30 \mathrm{BrPM}$. Finally, the same is done with a leak present. Each time a recording is performed, the PDL is connected to its flow visualization software to upload the results before the next flow condition is introduced.

The flow visualization software is then used to convert the pressure data and determine the average minute volume (MV) observed by the PDL during each trial. The results are grouped for each flow condition, then the average of each data group is compared between masks. To determine if significant difference in the population means is present, a two-sample t-test is performed, assuming equal variance. This statistical method establishes the consistency of results of the PDL between the two respirators. 


\subsection{Materials}

\subsubsection{The S.E.A. Group Pressure Data Logger}

The main device being observed in this study is the S.E.A. Group Pressure Data Logger. It is shown below in Figure 3.1.

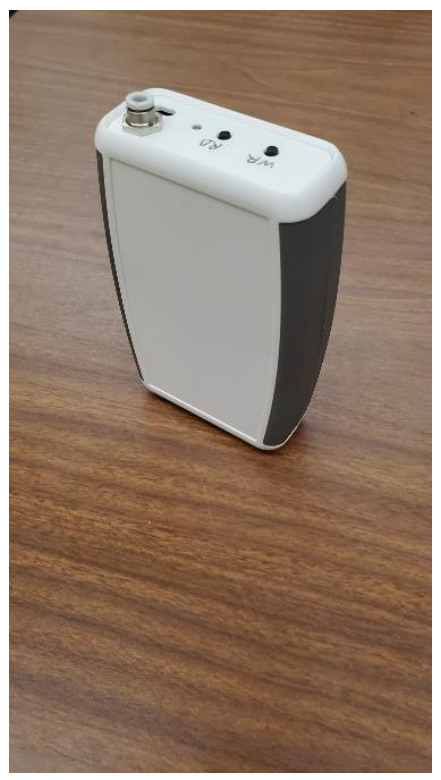

\section{Figure 3.1: S.E.A. Pressure Data Logger Unit}

The S.E.A. group developed this device to constantly measure the flow rate of a subject using a pressure sensor. The sensor instantaneously records the pressure differential between the inside and outside of a respirator with a sampling frequency of .02 seconds, or $50 \mathrm{~Hz}$. This provides a highly precise recreation of each breath cycle. This makes the device particularly effective as compared to other breathing flow recording devices [16]. The device is also favorable in terms of its form factor. The device can be worn by a HCW for long periods of a shift with little hassle.

The pressure data gathered by this device is accessed by uploading it to unique software provided by The S.E.A. Group. The data is initially presented as a graph of pressure vs. time, in units of $\mathrm{cmH} 2 \mathrm{O}$ and seconds. The data can then be manipulated within the software to display the recorded breathing flow in units of $\mathrm{L} / \mathrm{min}$ at each second. This data conversion first requires the user to calibrate the PDL to the specific respirator and filter being used. This process is called filter characterization, and it is described in more detail later, as well as in the user instructions manual included in Appendix A. Using the results of this characterization, the software is capable of also 
providing the user with work of breathing, inhaled volume, and exhaled volume. A screenshot example of the software is displayed in Figure 3.2.

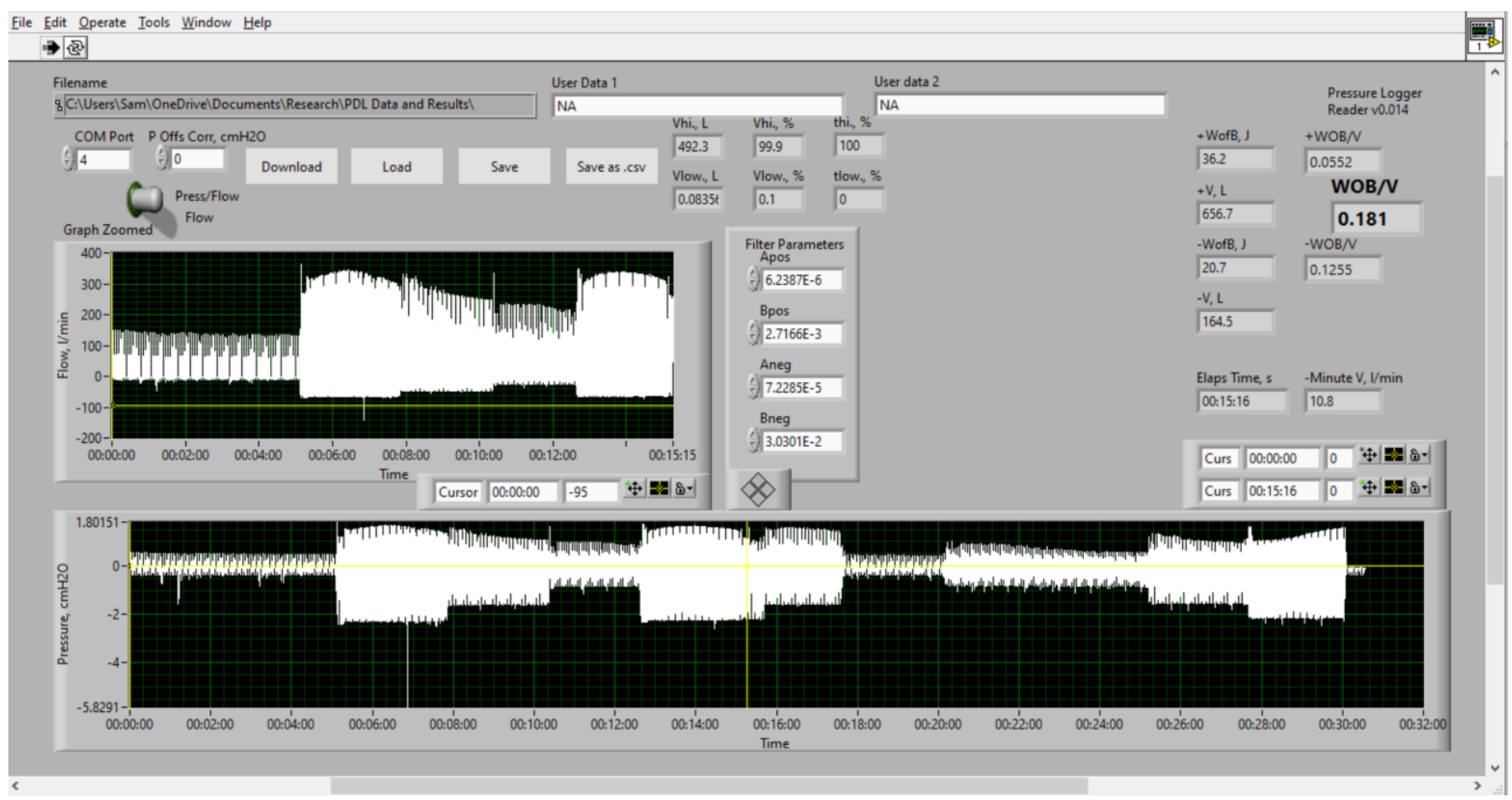

Figure 3.2: PDL software user interface.

For the device to be connected to a respirator, an adapter must be used. The adapters used in this study are shown in Figure 3.3 below. The adapter for the Sundström mask connects the PDL to an access port just inside an exit valve, while the adapter for the North mask connects the PDL to a port just inside an inlet preceded by one of the filter cartridges.
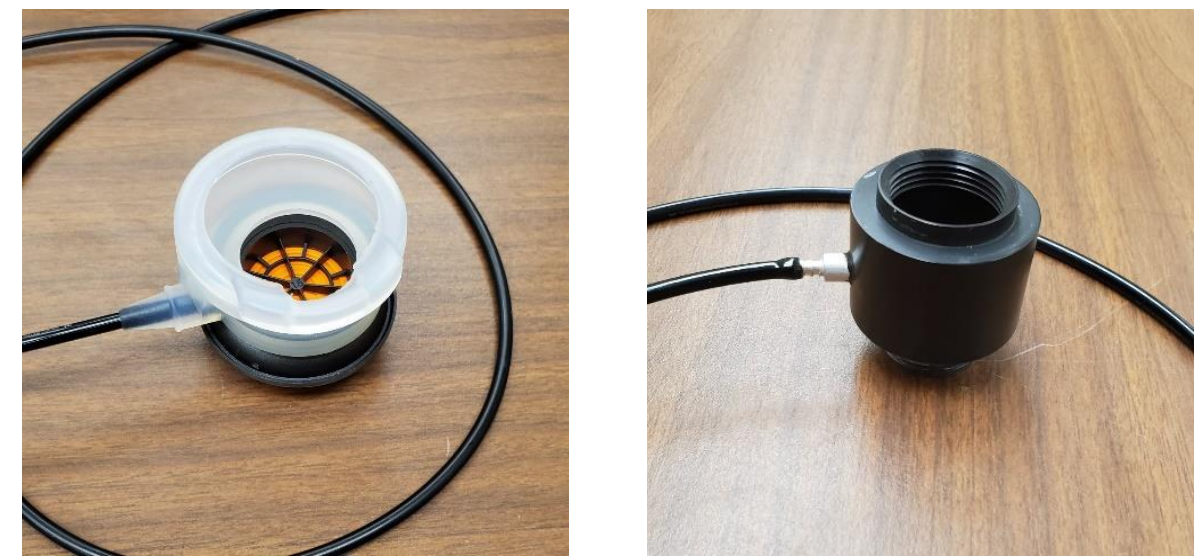

Figure 3.3: PDL connection adapters for Sundström (pictured left) and North (pictured right) respirators. 


\subsubsection{Sundström SR100 EHMR with P100 Filter Cartridge}

The S.E.A. Group packaged the SR100 mask with the PDL. While multiple sizes were supplied, a medium size mask was used for this experiment. Figure 3.4 shows the mask both without and with the PDL attached. The filter cartridge is a SR510, which is a general use P100 filter.
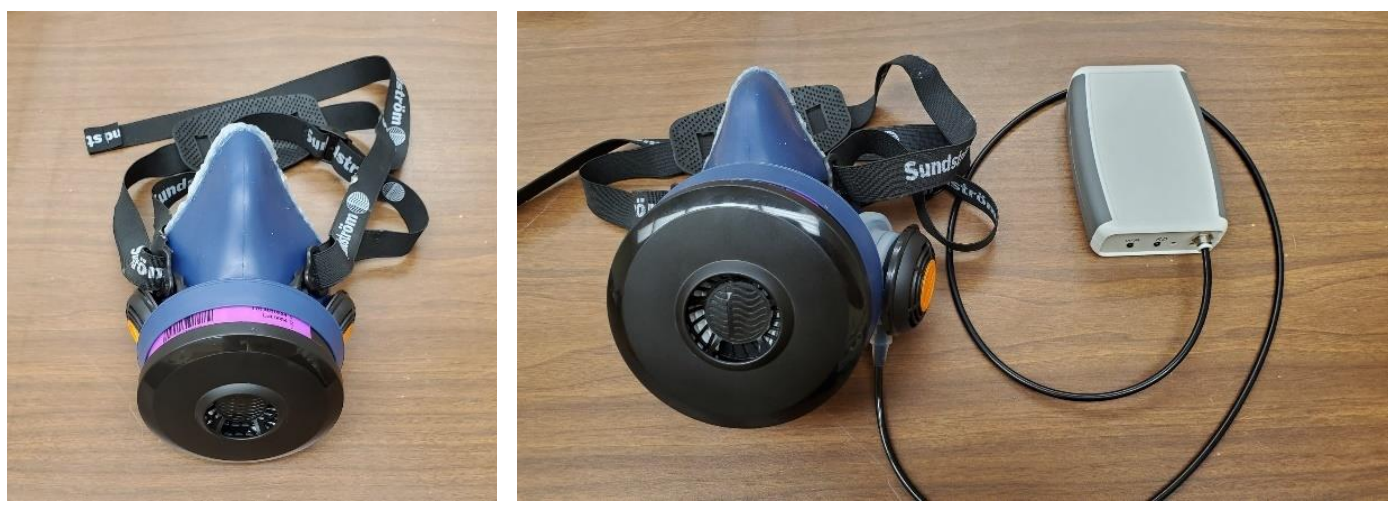

Figure 3.4: Sundström SR100 Respirator

\subsubsection{North 7700 Series EHMR with P100 Filter Cartridges}

This study utilizes a similar EHMR, the North 7700 series, for comparison. This mask is designed for similar use and is also equipped with P100 filter cartridges. However, the design of the facepiece is slightly different. There are two filter cartridges with inlet valves (one on either side of the facepiece) and one outlet valve in the center. This valve setup is opposite from that of the SR100. The 7700 series EHMR is pictured in Figure 3.5.
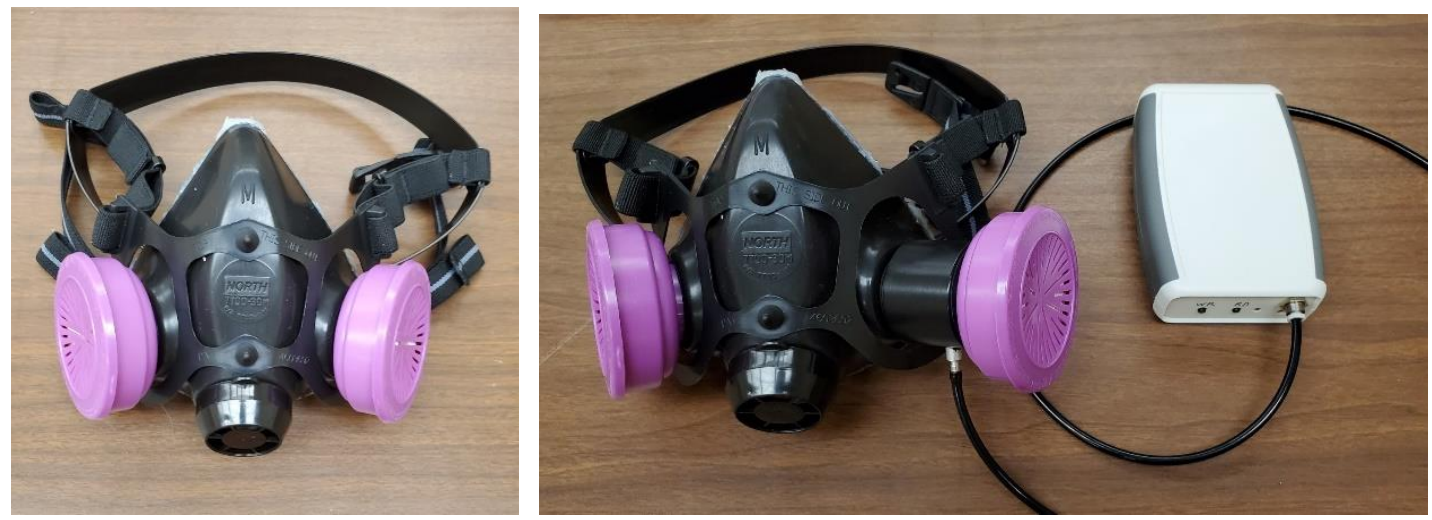

Figure 3.5: North 7700 Series Respirator 


\subsubsection{TSI 4000 Series High Performance Linear OEM Mass Flowmeter}

In order to perform the filter characterization and constant flow tests, a TSI 4000 series mass flowmeter is used to accurately control flow rate. This flowmeter is capable of accurately determining flow rate to within $2 \%$ of actual value [17]. It is designed to operate in flows of 0 $\mathrm{L} / \mathrm{min}$ to $100 \mathrm{~L} / \mathrm{min}$, which is adequate for its purpose in this study. The TSI 4000 series flowmeter is pictured in Figure 3.6.

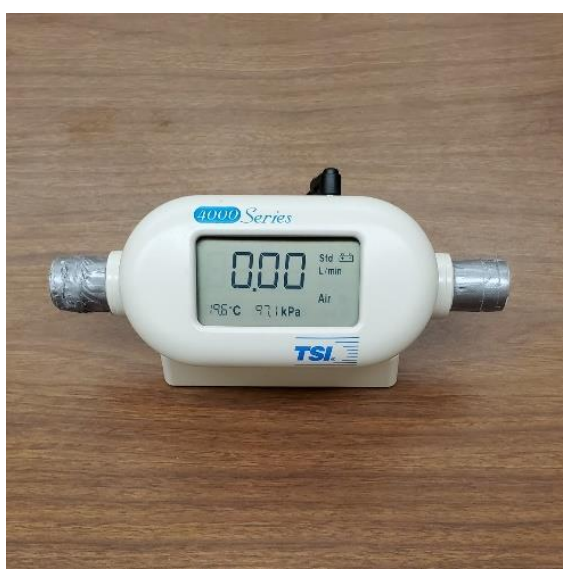

Figure 3.6: TSI 4000 Series Mass Flowmeter

\subsubsection{Airflow PVM100 Micromanometer}

For filter characterization, it is necessary to know the pressure inside each of the respirators as it is subjected to constant inhalation flow. The Airflow PVM100 Micromanometer is used during this process to continuously display the pressure, and according to specification it does so with accuracy of within less than 1\% [18]. The Airflow PVM100 Micromanometer is shown in Figure 3.7 . 


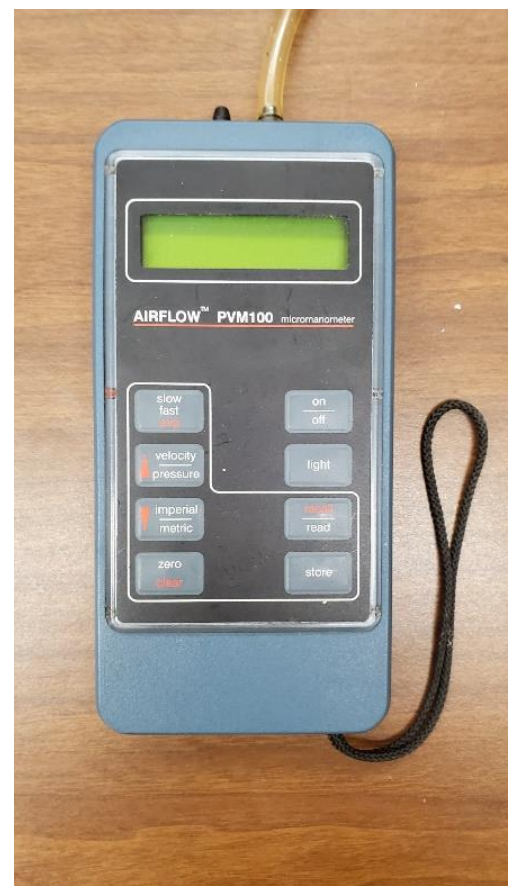

Figure 3.7: Airflow PVM100 Micromanometer

\subsubsection{Hans Rudolph Series 1101 Breathing Simulator}

For the simulated breathing evaluations performed in this study, a Hans Rudolph Series 1101 Breathing Simulator is used to generate a simulated breathing cycle. This device uses a mathematical lung model to control bellows located inside. This model is governed by lung parameters and breathing effort curve parameters, which are input by the user. These parameters are lung compliance, airway resistance, breath rate, effort slope, \% inhalation, amplitude, and tidal volume.

\subsection{Filter Characterization Method}

To properly convert the pressure recorded by the PDL into flow rate, the PDL software uses a filter characteristic curve. This curve is unique to the filter being used by the respirator. Varying shapes, sizes, and filter media lead to slight differences in pressure drop for a similar breathing flow. Essentially, a narrow, dense filter will require a larger pressure drop to bring in little air flow, whereas a wide, low-density filter will require much less of a pressure drop for that same amount of air flow. To account for this, the PDL utilizes a user-generated $2^{\text {nd }}$ order polynomial curve of pressure vs. airflow. 
Filter characterization was performed for each respirator in this study, one by one. Each time, the respirator is fully sealed to a mannikin head. The Airflow PVM100 micromanometer is attached to a port with access to the inside of the mannikin. The mannikin head is then connected to a laboratory vacuum nozzle. Since the airflow generated from this vacuum is unknown, a TSI 4000 Series mass flowmeter is connected in series between the mannikin and the vacuum. This setup is illustrated in Figure 3.8. While the setup in these photos shows the PDL attached to the respirator, this is not necessary for this method. The respirator can be used without the PDL and adapter to achieve similar results.

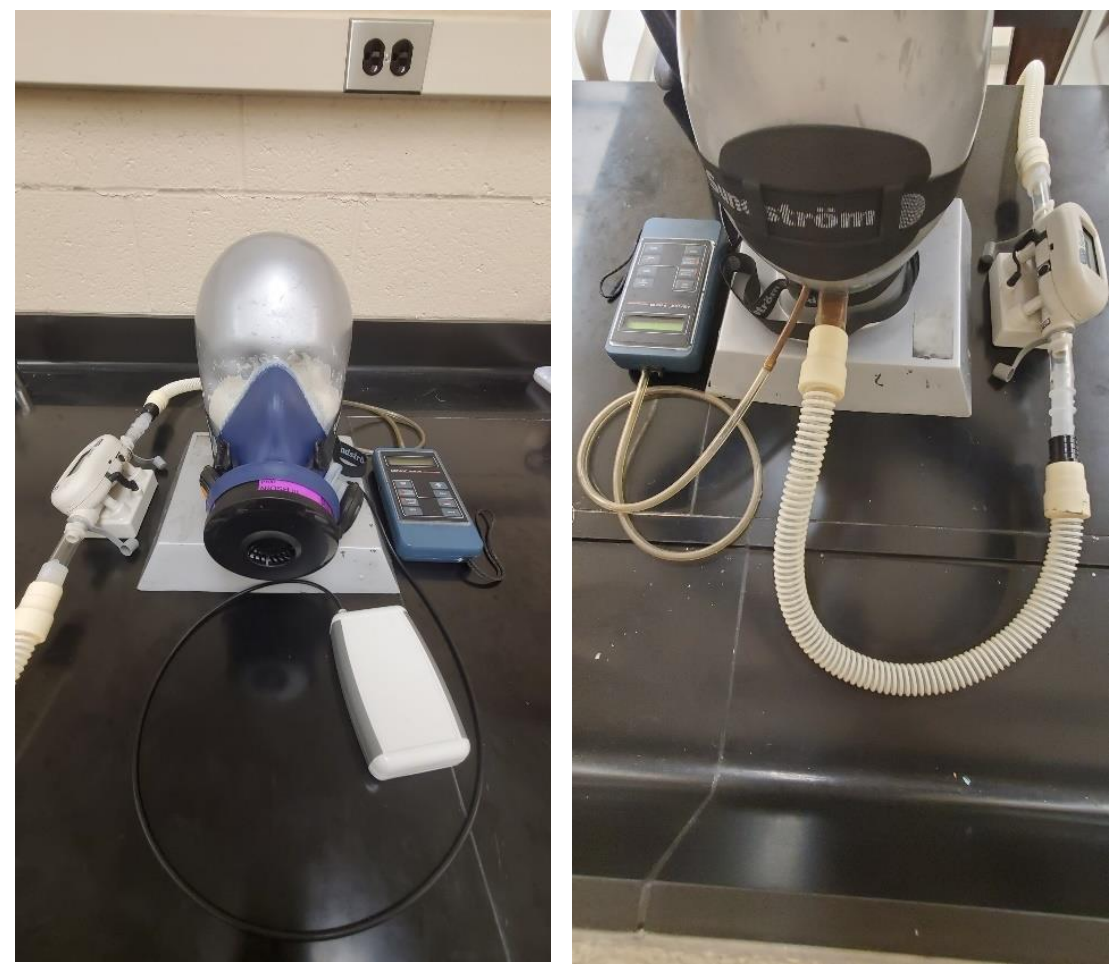

Figure 3.8: Filter Characterization Setup

Once setup is complete, the lab vacuum is turned on. With the guide of the mass flowmeter display, the airflow is set to remain constant at various strengths. Starting at $0 \mathrm{~L} / \mathrm{min}$, the flow is increased in increments of $10 \mathrm{~L} / \mathrm{min}$ to a maximum of $80 \mathrm{~L} / \mathrm{min}$. While the airflow is held constant at each increment, the pressure readout of the micromanometer is recorded. The pressure and flow rate data are then entered into a Microsoft Excel spreadsheet, and a $2^{\text {nd }}$ order polynomial best-fit curve is produced. The equation associated with this curve is in the form of $a x^{2}+b x+c$. The ' $a$ ' and ' $b$ ' coefficients of this equation are input as 'Aneg' and 'Bneg' on the PDL software. The 
'Apos' and 'Bpos' parameters can be obtained using a similar method while reversing airflow to simulate exhalation. However, S.E.A. notes that, since exhalation valves offer significantly less resistance, exhalation flow is more unpredictable and difficult to measure accurately. Thus, values for Apos and Bpos can be kept constant (see the PDL User Instructions in Appendix A for more detail).

\subsection{Constant Flow Evaluation Method}

With the pressure drop and airflow relationship fully characterized for each respirator, evaluation of the PDL can begin. The PDL is first evaluated at a constant rate of airflow. The setup for this evaluation is similar to the setup used in filter characterization. In this setup, however, the PDL is attached to the respirator using its corresponding adapter. The constant flow evaluation setup is shown for each respirator in Figure 3.9.
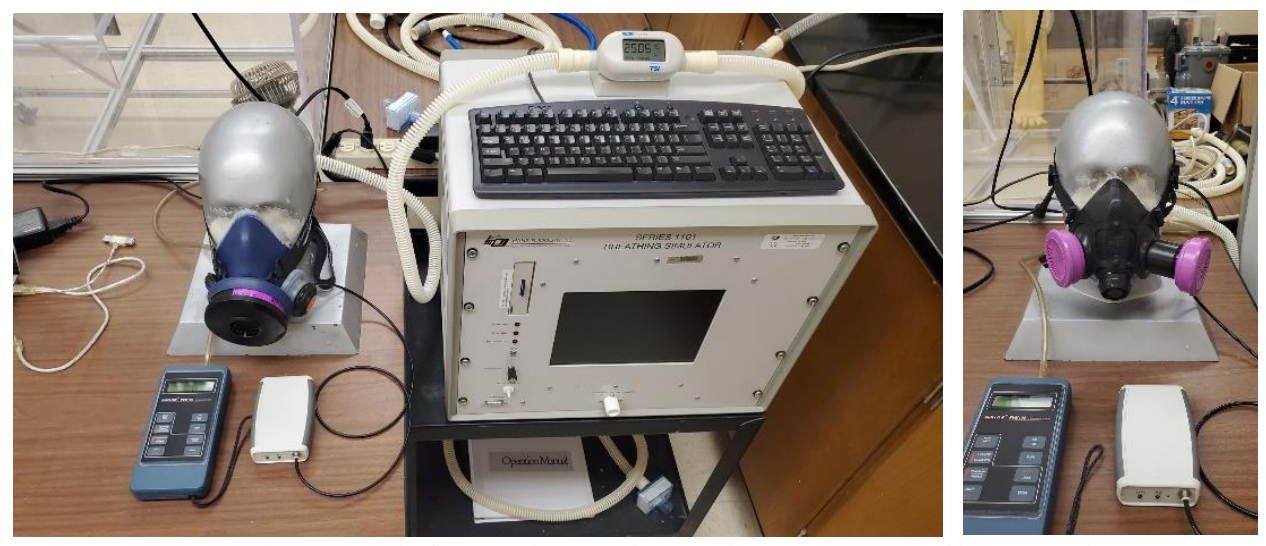

Figure 3.9: Sundström (left) and North (right) constant flow evaluation setup

During this evaluation, the respirators are exposed to flows of $10,25,50$, and $75 \mathrm{~L} / \mathrm{min}$. First, the PDL is initialized. Once it is recording the vacuum is set to the first flow rate. Each flow rate is used 3 times, for a total of 12 trials. The 12 trials are performed in random order for 2 minutes each. Total testing time for each respirator during this evaluation is roughly 30 minutes, accounting for the time taken to switch between flow rates. Each time after recording, the PDL is connected to a PC running the PDL software and the data is uploaded for analysis.

The second evaluation is the same as the first, but a leak is formed in the seal between the respirator and the mannikin. This is done to evaluate the performance of the PDL when the seal 
condition is different than that of filter characterization. The leak introduced to each respirator is similar in size, roughly $0.75 \mathrm{~cm}$. Once the leak is introduced, the respirators are exposed to the same flow rates in 12 random trials. Once again, results are uploaded after each recording session. The leaks created on each respirator are shown below in Figure 3.10.
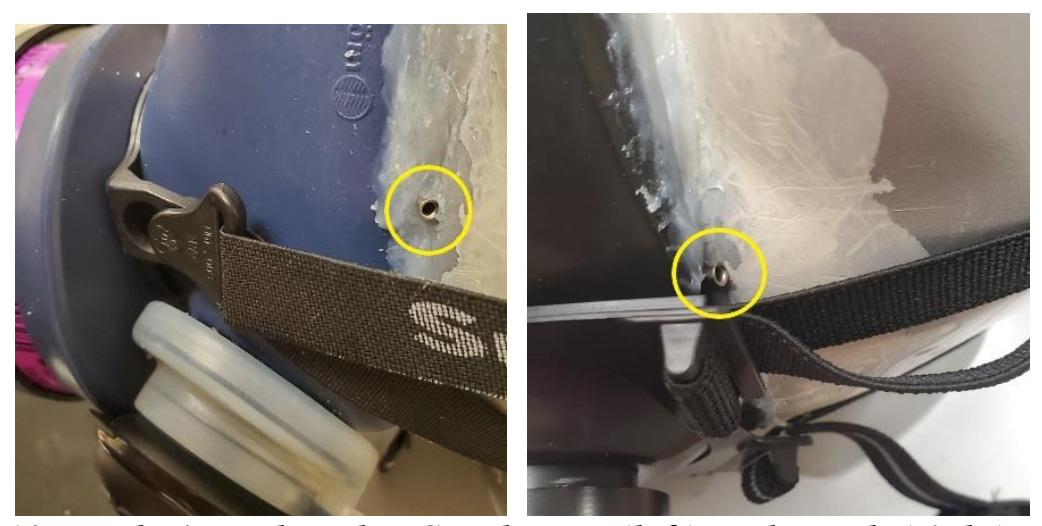

Figure 3.10: Leaks introduced to Sundström (left) and North (right) respirators

\subsection{Simulated Breathing Evaluation Method}

The next evaluation involves the use of a breathing simulator. This method tests the PDLs consistency in a more realistic situation, as air flow rate varies greatly over the course of a breathing cycle. To use the Hans Rudolph 1101 Series Breathing Simulator, various lung and breathing effort parameters must first be input. Typical values for lung parameters were selected based on values given in the user manual. The breathing effort parameters were set with specific values of respiratory MV in mind. Using tidal volume (TV) and respiratory rate (RR), MV is calculated using Equation 3.1.

$$
M V=T V \times R R
$$

The respirators were tested under four MV values: $5 \mathrm{~L} / \mathrm{min}, 12.5 \mathrm{~L} / \mathrm{min}, 25 \mathrm{~L} / \mathrm{min}$, and $37.5 \mathrm{~L} / \mathrm{min}$. These range from typical values at rest to values observed during manual labor [19]. The values for all parameters used during the evaluation of each mask are shown in Table 3.1. 
Table 3.1: Lung and breathing effort parameters

\begin{tabular}{|c|c|c|c|c|c|c|c|c|}
\hline \multirow{4}{*}{ Parameters (units) } & \multicolumn{8}{|c|}{ Respirator } \\
\hline & \multicolumn{4}{|c|}{ Sundström SR100 } & \multicolumn{4}{|c|}{ North 7700 Series } \\
\hline & \multicolumn{8}{|c|}{ Minute Volume (L/min) } \\
\hline & 5 & 12.5 & 25 & 37.5 & 5 & 12.5 & 25 & 37.5 \\
\hline Airway Resistance $(\mathrm{cmH} 2 \mathrm{O} / \mathrm{L} / \mathrm{s})$ & \multicolumn{4}{|c|}{10} & \multicolumn{4}{|c|}{10} \\
\hline Lung Compliance (mL/cmH2O) & \multicolumn{4}{|c|}{40} & \multicolumn{4}{|c|}{40} \\
\hline Respiratory Rate (BrPM) & 15 & 20 & 25 & 30 & 15 & 20 & 25 & 30 \\
\hline Amplitude (cmH2O) & 9 & 17 & 28 & 38 & 9 & 17 & 28 & 38 \\
\hline Effort Slope (cmH2O) & 9 & 11 & 15 & 18 & 9 & 11 & 15 & 18 \\
\hline$\%$ Inhale & 35 & 40 & 42.5 & 45 & 35 & 40 & 42.5 & 45 \\
\hline Tidal Volume (mL) & 333 & 625 & 1000 & 1250 & 333 & 625 & 1000 & 1250 \\
\hline
\end{tabular}

These four breathing cycles are each applied 3 times, for 12 total trials. Similar to the constant flow method, the order of these trials are randomized and they last 2 minutes each. The same inputs are used for each respirator once a leak is introduced. This leak is consistent with the leak introduced for the second group of trials. After each 30-minute recording session, the PDL data is uploaded to a PC.

\subsection{Data Analysis Method}

The raw data collected from the PDL is converted from pressure vs. time into flow rate vs. time using the characteristic curve parameters found in filter characterization. The readouts of the raw data can be found in Appendix B. The software is then used to determine the average flow rate (MV) for each individual 2-minute trial. These averages are grouped according to respirator and flow condition.

For each of the four flow conditions, the population means for the Sundström SR100 and North 7700 Series are compared using a two sample t-test assuming equal variance. This analysis was performed using a Microsoft Excel spreadsheet. The test statistic for this method is calculated using Equation 3.2. 


$$
T=\frac{\bar{X}_{1}-\bar{X}_{2}}{s_{p} \sqrt{1 / N_{1}+1 / N_{2}}}
$$

In Equation 3.2, $\bar{X}_{1}$ and $X_{2}$ are the sample means, and $N_{1}$ and $N_{2}$ are the number of occurrences in each sample. $\mathrm{s}_{\mathrm{p}}$ is the pooled variance of the system. Because variance is assumed to be equal between the two populations, it is calculated as one value for all data, using Equation 3.3.

$$
s_{p}=\sqrt{\frac{\left(N_{1}-1\right) s_{1}^{2}+\left(N_{2}-1\right) s_{2}^{2}}{N_{1}+N_{2}-2}}
$$

The null hypothesis is that there is no significant difference in the population means of data collected on each respirator $\left(\mathrm{H}_{0}=\mu_{1}-\mu_{2}=0\right)$. A significant difference in the data $(\mathrm{p}<0.05)$ would suggest that the alternative hypothesis, $\mathrm{H}_{\mathrm{A}}$, is satisfied, and that the PDL is inconsistent and lacks accuracy when being used on different EHMRs. 


\section{Results}

\subsection{Filter Characterization Results}

The data gathered to generate the filter characteristic curves is shown in Table 4.1. The pressure shown is negative gauge pressure, the pressure drop across the filter.

Table 4.1: Filter characterization data

\begin{tabular}{c|c|c}
\multirow{2}{*}{ Flow Rate (L/min) } & \multicolumn{2}{|c}{ Pressure (cmH2O) } \\
\hline 0 & Sundström SR100 & North 7700 Series \\
\hline 10 & 0.135 & 0 \\
20 & 0.295 & 0.236 \\
30 & 0.450 & 0.515 \\
40 & 0.625 & 0.775 \\
50 & 0.813 & 1.049 \\
60 & 1.016 & 1.356 \\
70 & 1.229 & 1.666 \\
80 & 1.450 & 2.001 \\
& & 2.337 \\
\hline
\end{tabular}

The characteristic curves associated with each respirator are shown in Figures 4.1 and 4.2, along with their polynomial equation. Aneg is $6.1569 \times 10^{-5}$ and Bneg is $1.3219 \times 10^{-2}$ for the Sundström SR100. For the North 7700 Series, Aneg is $6.9603 \times 10^{-5}$ and Bneg is $2.3642 \times 10^{-2}$. 


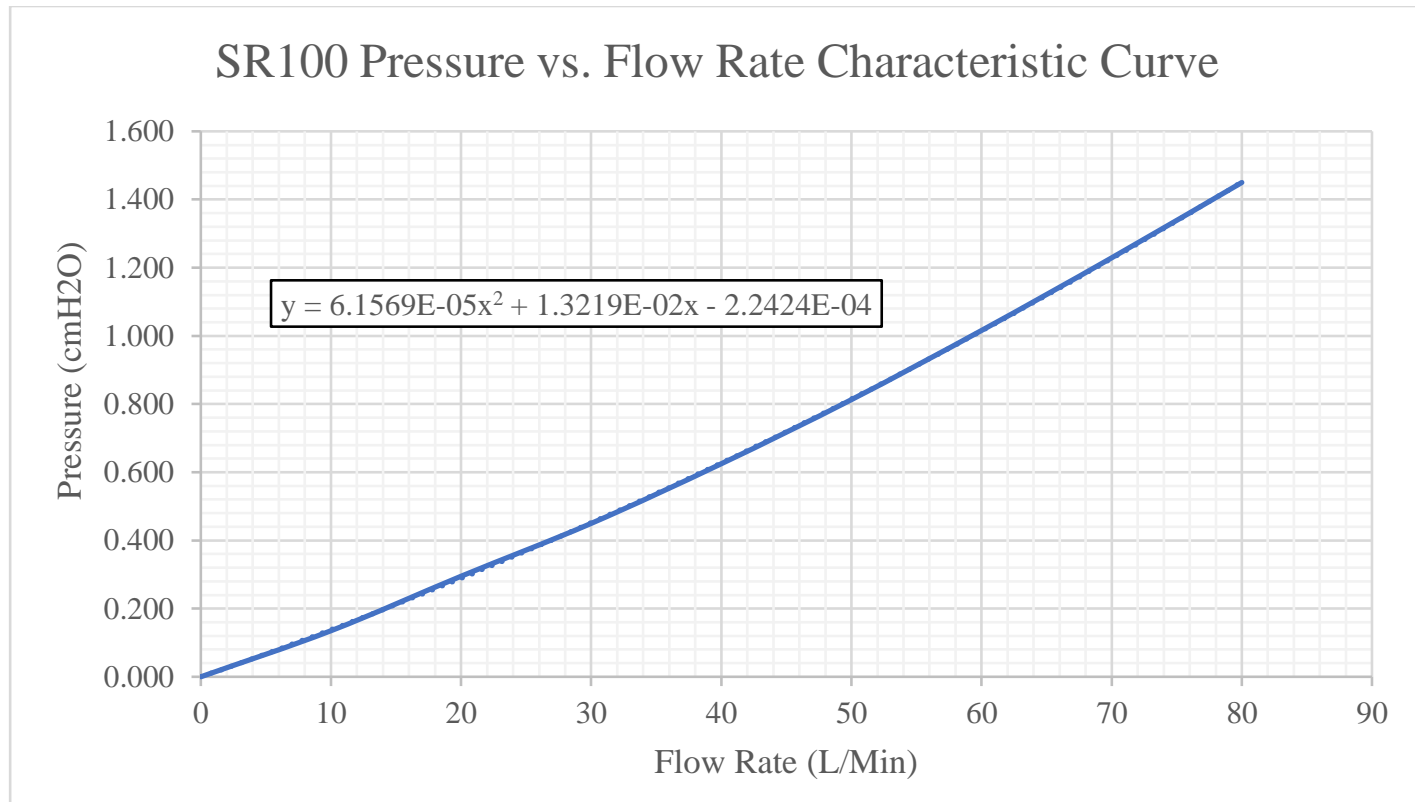

Figure 4.1: Sundström SR100 filter characteristic curve

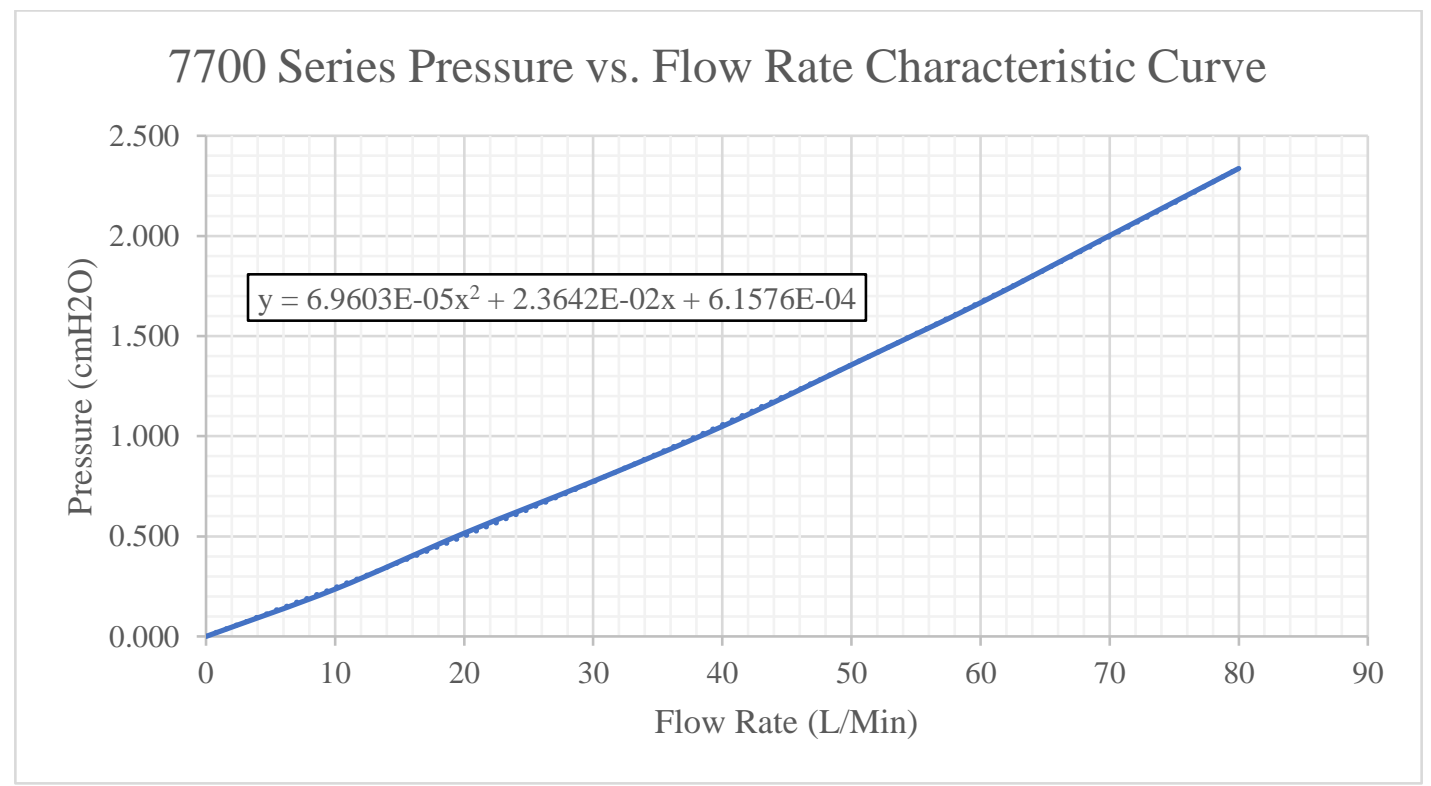

Figure 4.2: North 7700 Series filter characteristic curve 


\subsection{Constant Flow Evaluation Results}

The detailed data records for all trials can be found in Appendix B. Table 4.2 displays the averages of each trial for both respirators during sealed, constant flow.

Table 4.2: Sealed, constant flow MV averages

\begin{tabular}{c|c|c}
\multirow{2}{*}{$\begin{array}{c}\text { Testing Flow Rate } \\
(\mathrm{L} / \mathrm{min})\end{array}$} & \multicolumn{2}{|c}{ Average MV Calculated by PDL Software (L/min) } \\
\cline { 2 - 3 } & Sundström SR100 & North 7700 \\
\hline \multirow{3}{*}{10} & 9.9 & 11.3 \\
& 10 & 11.3 \\
\multirow{2}{*}{25} & 25.6 & 11.2 \\
\hline \multirow{3}{*}{50} & 26.3 & 26.5 \\
& 25.8 & 25.8 \\
& 51 & 26 \\
\hline \multirow{2}{*}{75} & 50.8 & 49.9 \\
& 51.1 & 49.7 \\
& 75.3 & 51.4 \\
\hline & 75.2 & 79 \\
& 75.3 & 77.1 \\
& & 73.3 \\
& &
\end{tabular}

The MV returned by the PDL software was never more than 3\% different than the testing flow rate for either respirator. These two data groupings were compared using a hypothesis test of difference in population means. The results of the two sample t-test analysis for the sealed, constant flow condition are displayed in Table 4.3. 
Table 4.3: Sealed, constant flow statistical analysis results

\begin{tabular}{c|c|c} 
& Sundström & North \\
\hline $\begin{array}{c}\text { Observations } \\
(\mathrm{N})\end{array}$ & 12 & 12 \\
$\begin{array}{c}\text { Sample mean } \\
(\mathrm{X})\end{array}$ & 40.525 & 41.042 \\
$\begin{array}{c}\text { Pooled variance } \\
\left(\mathrm{s}_{\mathrm{p}}\right)\end{array}$ & 671 \\
$\begin{array}{c}\text { Degrees of freedom } \\
(\mathrm{df})\end{array}$ \\
$\begin{array}{c}\text { Test statistic } \\
(\mathrm{T})\end{array}$ \\
\begin{tabular}{|c} 
Critical value \\
$\left(\mathrm{T}_{\text {crit }}\right)$
\end{tabular} & 22 \\
\end{tabular}

Both sample means for this flow condition are less than 3\% different from the average test flow rate of $40 \mathrm{~L} / \mathrm{min}$. Since $|\mathrm{T}|<\mathrm{T}_{\text {crit }}, \mathrm{H}_{0}$ is accepted. MV averages for the leaking, constant flow condition are shown in Table 4.4.

Table 4.4: Leaking, constant flow MV averages

\begin{tabular}{c|c|c}
$\begin{array}{c}\text { Testing Flow Rate } \\
(\mathrm{L} / \mathrm{min})\end{array}$ & Average MV Calculated by PDL Software (L/min) \\
\cline { 2 - 3 } & Sundström SR100 & North 7700 \\
\hline \multirow{3}{*}{10} & 9.4 & 8.5 \\
& 9.2 & 9 \\
25 & 9.2 & 9.1 \\
\hline \multirow{3}{*}{50} & 24.9 & 19.5 \\
& 22.7 & 19 \\
& 23.9 & 18.9 \\
\hline \multirow{3}{*}{75} & 46.7 & 40.5 \\
& 46.1 & 38.4 \\
& 45.4 & 37.8 \\
\hline & 66.5 & 60.2 \\
& 65.8 & 58.4 \\
& 65.4 & 56.7
\end{tabular}


The MV returned during this set of observations exhibited lower values at all flow rates compared to the sealed observations. The statistical analysis results are shown in Table 4.5. Although the sample means are now significantly lower, $|\mathrm{T}|<\mathrm{T}_{\text {crit }}$ and $\mathrm{H}_{0}$ is again accepted.

Table 4.5: Leaking, constant flow statistical analysis results

\begin{tabular}{c|c|c} 
& Sundström & North \\
\hline $\begin{array}{c}\text { Observations } \\
(\mathrm{N})\end{array}$ & 12 & 12 \\
$\begin{array}{c}\text { Sample mean } \\
(\mathrm{X})\end{array}$ & 36.267 & 31.333 \\
$\begin{array}{c}\text { Pooled variance } \\
\left(\mathrm{s}_{\mathrm{p}}\right)\end{array}$ & \multicolumn{2}{|c|}{451} \\
$\begin{array}{c}\text { Degrees of freedom } \\
(\mathrm{df})\end{array}$ \\
$\begin{array}{c}\text { Test statistic } \\
(\mathrm{T})\end{array}$ \\
$\begin{array}{c}\text { Critical value } \\
\left(\mathrm{T}_{\text {crit }}\right)\end{array}$ & 22 \\
\end{tabular}




\subsection{Simulated Breathing Evaluation Results}

The average MV recorded during each trial of the sealed, simulated breathing flow condition is shown in Table 4.6.

Table 4.6: Sealed, simulated breathing MV averages

\begin{tabular}{|c|c|c|}
\hline \multirow{2}{*}{$\begin{array}{l}\text { Test MV based on } \\
\text { Lung and effort } \\
\text { parameters ( } \mathrm{L} / \mathrm{min})\end{array}$} & \multicolumn{2}{|c|}{ Average MV Calculated by PDL Software (L/min) } \\
\hline & Sundström SR100 & North 7700 \\
\hline \multirow{3}{*}{5} & 5.1 & 5.0 \\
\hline & 5.9 & 4.9 \\
\hline & 5.9 & 4.9 \\
\hline \multirow{3}{*}{12.5} & 11.3 & 10.6 \\
\hline & 11.4 & 10.3 \\
\hline & 11.4 & 10.5 \\
\hline \multirow{3}{*}{25} & 21.4 & 21.1 \\
\hline & 21.7 & 19.7 \\
\hline & 21.6 & 19.9 \\
\hline \multirow{3}{*}{37.5} & 29.2 & 30.5 \\
\hline & 29.2 & 29.2 \\
\hline & 28.6 & 29.1 \\
\hline
\end{tabular}

The results of statistical analysis are shown in Table 4.7. The test statistic is 0.148 , which is well under the critical value of 2.074. The null hypothesis is accepted for sealed, simulated breathing as well. 
Table 4.7: Sealed, simulated breathing statistical analysis results

\begin{tabular}{c|c|c} 
& Sundström & North \\
\hline $\begin{array}{c}\text { Observations } \\
(\mathrm{N})\end{array}$ & 12 & 12 \\
$\begin{array}{c}\text { Sample mean } \\
(\mathrm{X})\end{array}$ & 16.892 & 16.308 \\
$\begin{array}{c}\text { Pooled variance } \\
\left(\mathrm{s}_{\mathrm{p}}\right)\end{array}$ & 93 \\
$\begin{array}{c}\text { Degrees of freedom } \\
(\mathrm{df})\end{array}$ \\
$\begin{array}{c}\text { Test statistic } \\
(\mathrm{T})\end{array}$ \\
\begin{tabular}{|c} 
Critical value \\
$\left(\mathrm{T}_{\text {crit }}\right)$
\end{tabular} & 22 \\
\end{tabular}

The leaking simulated breathing flow data is displayed in Table 4.8. This is the fourth and final flow condition used in the evaluation of the PDL.

Table 4.8: Leaking, simulated breathing MV averages

\begin{tabular}{c|c|c} 
Test MV based on & \multicolumn{2}{|c}{ Average MV Calculated by PDL Software (L/min) } \\
\cline { 2 - 3 } $\begin{array}{c}\text { Lung and effort } \\
\text { parameters (L/min) }\end{array}$ & Sundström SR100 & North 7700 \\
\hline \multirow{3}{*}{5} & 5.5 & 4.8 \\
& 5.7 & 4.8 \\
\multirow{3}{*}{12.5} & 5.6 & 5.0 \\
\hline \multirow{3}{*}{25} & 9.9 & 8.6 \\
& 9.8 & 8.6 \\
& 9.9 & 8.6 \\
\hline \multirow{3}{*}{37.5} & 19.1 & 15.7 \\
& 18.6 & 15.5 \\
& 17.9 & 15.2 \\
\hline & 25.5 & 23.2 \\
& 24.3 & 21.9 \\
& 24.5 & 21.9
\end{tabular}


The leaking flow condition again exhibits significantly lower values of MV compared to the sealed conditions. While the average test MV of the flow condition is $20 \mathrm{~L} / \mathrm{min}$, the sample means from each respirator are under $15 \mathrm{~L} / \mathrm{min}$. The statistical analysis results are shown in Table 4.9. As with each other flow condition, $|\mathrm{T}|<\mathrm{T}_{\text {crit }}$ and $\mathrm{H}_{0}$ is accepted.

Table 4.9: Leaking, simulated breathing statistical analysis results

\begin{tabular}{c|c|c} 
& Sundström & North \\
\hline $\begin{array}{c}\text { Observations } \\
(\mathrm{N})\end{array}$ & 12 & 12 \\
$\begin{array}{c}\text { Sample mean } \\
(\mathrm{X})\end{array}$ & 14.692 & 12.817 \\
$\begin{array}{c}\text { Pooled variance } \\
\left(\mathrm{s}_{\mathrm{p}}\right)\end{array}$ & 55 \\
$\begin{array}{c}\text { Degrees of freedom } \\
(\mathrm{df})\end{array}$ \\
$\begin{array}{c}\text { Test statistic } \\
(\mathrm{T})\end{array}$ \\
$\begin{array}{c}\text { Critical value } \\
\left(\mathrm{T}_{\text {crit }}\right)\end{array}$ & 22 \\
\end{tabular}




\section{Discussion and Conclusions}

\subsection{Filter Characterization}

The filter characterization data in Table 4.1 shows a clear difference in the pressure drop of each respirator with all flow rates. More specifically, the pressure drop inside of the North 7700 Series respirator was consistently $60 \%$ higher for the same tested flow rates compared to the Sundström respirator. The Sundström SR510 filter is tested to have a pressure drop of $1.44 \mathrm{cmH} 2 \mathrm{O}$ at a flow rate of $85 \mathrm{~L} / \mathrm{min}$, according to its specifications [20]. The SR510 studied here exhibited a pressure drop of $1.45 \mathrm{cmH} 2 \mathrm{O}$ at a flow of just $80 \mathrm{~L} / \mathrm{min}$. This slight difference is likely due to difference in the seal, testing environment, slight error in the Airflow PVM100 micromanometer, or change in breathing resistance due to the SR100 respirator. The higher values of pressure drop for the North P100 filter cartridges are due to a few factors. First, the width of the pre-filter entrance and filter media is much smaller for the North P100 filters. This allows less space for the air to flow through to the space with lower pressure, which leads to increased airflow resistance. Despite there being two inhalation routes, the total area allowed by these routes is smaller than the area allowed by the Sundström SR100 and SR510. The layout of these inhalation valves may also contribute to breathing resistance. On the North 7700 , the inhalation valves are placed on each side of the mask, away from the mouth. This creates a less direct route for air to travel, which consequently increases resistance.

These results illustrate the unquestionable importance of filter characterization. Since the PDL is inherently a pressure recording device, it is imperative that a relationship between pressure drop and flow rate is developed each time a new filter and respirator combination is monitored. The ability of this process to properly characterize this relationship is a key factor in determining whether this PDL can be used with varying respirators.

\subsection{PDL Consistency and Accuracy Across Different Respirators}

For all of the four flow conditions, the results of statistical analysis showed that the PDL demonstrated similar readings ( $p>0.05$ ) between the North and Sundström respirators. The device showed the greatest consistency between devices during sealed, constant flow. This recording 
environment is most ideal for the PDL. Air flow, and thus, pressure, is most predictable and stable during this evaluation. The PDL showed the least consistency between respirators when exposed to simulated breathing with a leak present. This is important to note, because if this condition is most similar to a realistic recording environment. The accuracy of the PDL to return similar values to the tested flow rate was slightly higher with the Sundström respirator in most trials. The PDL was most accurate during sealed constant flow and least accurate during simulated breathing with a leak. Again, this is due to the disorganized nature of air flow during normal breathing patterns.

In general, the PDL lost consistency in results between respirators as leaks were introduced. The relationship between pressure and flow rate developed in filter characterization was broken down. The breakdown due to imperfect seal conditions may affect the PDL in different ways on different respirators due to varying mask design factors and filter properties.

\subsection{PDL Consistency and Accuracy Across Different Seal Conditions}

The consistency of the PDL was also evaluated across different seal conditions for the same respirator. The PDL showed insignificant difference in these results as well. However, it is evident that seal condition has a greater effect on the consistency of the PDL than the model of respirator being used. Comparing the sealed simulated breathing flow condition of the North 7700 to the leaking simulated breathing flow condition yielded a T-statistic of 1.001, which is considerably higher than any value observed when comparing results across respirator models. Proper implementation of user seal-checks would be advised to help prevent data distortion. Because the filter characterization process is performed with ideal seal conditions, it is important to maintain a good seal for the duration of monitoring.

\subsection{Recommendations}

Due to limitations with equipment, only the PDL was only tested using two models of respirators. To develop a better understanding of the PDLs capabilities, there should be testing done on more respirators of varying mask design. This could progress into the inclusion of EHMRs converted into PAPRs. Future studies involving this PDL should also involve using the device on multiple respirator models in a simulated healthcare environment with live subjects. 
The laboratory vacuum used in this study could produce a maximum flow rate of 100 $\mathrm{L} / \mathrm{min}$. Although this is higher than any MV tested, peak inspiratory flow (PIF) surpassed 100 $\mathrm{L} / \mathrm{min}$ in tests using the breathing simulator at higher workload. The S.E.A. Group indicates that filter characterization should be performed at flow rates up to $400 \mathrm{~L} / \mathrm{min}$ (Appendix A). This value is higher than what is necessary for monitoring HCWs, but higher values of flow rate should be used to include PIF. The addition of Apos and Bpos in filter characterization could be explored to see if this increases PDL accuracy. The exhalation valves are different on each respirator and although the exhalation flow is more erratic, calculated values are likely to produce more accurate results.

\subsection{Conclusion}

The S.E.A. PDL was capable of producing consistent results between respirator models when monitoring constant flow and simulated breathing. The ability to accurately characterize a pressure vs. flow relationship using the PDL software proved to be a key factor in developing reliability. The PDL also proved to be consistent when monitoring while exposed to different seal conditions. Seal condition proved to be more of a concern with data distortion than the model of respirator being used. The results of this study indicate that this device has the potential of being used to monitor breathing flow of HCWs. However, careful consideration should be taken to maintaining a proper seal with respirators monitored by this device. New design possibilities of PAPRs are currently being discussed to minimize issues with cost and user experience. The data collected by this device could prove to be useful in developing new PAPR standards and technology that would require lower supply flow rate, which would potentially make PAPRs quieter, less expensive, and easier to use for HCWs. 


\section{References}

1. OSHA (2015) OSHA Technical Manual (OTM)|Section VIII: Chapter 2: Respiratory Protection | Occupational Safety and Health Administration, www.osha.gov/dts/osta/otm/otm_viii/otm_viii_2.html\#5

2. "100 Years of Respiratory Protection History." Centers for Disease Control and Prevention, National Institute of Occupational Safety and Health, 31 July 2019, www.cdc.gov/niosh/npptl/Respiratory-Protection-history.html

3. Timeline of OSHA's 40 year History. Retrieved 11/15/2019 from https://www.osha.gov/osha40/timeline.html.

4. OSHA Respiratory Protection Standard. Retrieved November 12, 2019, from https://www.osha.gov/laws-regs/regulations/standardnumber/1910/1910.134.

5. NIOSH seeking partners for project to redesign PAPR for health care workers. (2019, July 10). Safety and Health Magazine. Retrieved November 12, 2019 from: https://www.safetyandhealthmagazine.com/articles/18641-niosh-seeking-partners-forproject-to-redesign-papr-for-health-care-workers

6. Bloom, David E, and Daniel Cadarette. "Infectious Disease Threats in the Twenty-First Century: Strengthening the Global Response.” Frontiers in immunology vol. 10 549. 28 Mar. 2019, doi:10.3389/fimmu.2019.00549

7. K. Wizner, L. Stradtman, D. Novak, et al.Prevalence of respiratory protective devices in us health care facilities: implications for emergency preparedness. Workplace Health Safe, 64 (2016), pp. 359-368

8. W. A. Burgess, P. C. Reist. Supply rates for powered air-purifying respirators. Am Ind Hyg Assoc J. 1969 Jan-Feb; 30(1): 1-6. doi: 10.1080/00028896909343092

9. International Organization for Standardization. (2016). Respiratory protective devices Human factors - Part 1: Metabolic rates and respiratory flow rates (ISO/TS 16976-1:2015). Retrieved from https://www.iso.org/standard/67530.html

10. Khoo, K. , Leng P., Ibrahim, I. B. and Lim, T. (2005), The changing face of healthcare worker perceptions on powered air-purifying respirators during the SARS outbreak. Respirology, 10: 107-110. doi:10.1111/j.1440-1843.2005.00634.X

11. Baig, Aliya S. et al. Health care workers' views about respirator use and features that should be included in the next generation of respirators. American Journal of Infection Control, Volume 38, Issue 1, 18 - 25 Retrieved November 16, 2019 from https://www.ajicjournal.org/article/S0196-6553(09)00891-8/fulltext 
12. Institute of Medicine. The Use and Effectiveness of Powered Air Purifying Respirators in Health Care: Workshop Summary. Washington (DC): National Academies Press (US); 2015 May 7. Retrieved November 17, 2019 from: https://www.ncbi.nlm.nih.gov/books/NBK294215/ doi: 10.17226/18990

13. Lim, E. C., Seet, R. C., Lee, K., Wilder-Smith, E. P., Chuah, B. Y. and Ong, B. K. (2006), Headaches and the N95 face-mask amongst healthcare providers. Acta Neurologica Scandinavica, 113: 199-202. doi:10.1111/j.1600-0404.2005.00560.x Retrieved November 15, 2019 from: https://onlinelibrary.wiley.com/doi/abs/10.1111/j.1600-0404.2005.00560.x

14. Hines, Stella E. et al. User acceptance of reusable respirators in health care. American Journal of Infection Control. Volume 47, Issue 6. 2019. Pages 648-655. https://doi.org/10.1016/j.ajic.2018.11.021. Retrieved November 14, 2019 from: https://www.sciencedirect.com/science/article/pii/S0196655318311428

15. Roberge, Raymond J. Evaluation of the rationale for concurrent use of N95 filtering facepiece respirators with loose-fitting powered air-purifying respirators during aerosolgenerating medical procedures. American Journal of Infection Control. Volume 36, Issue 2. 2008. Pages 135-141. https://doi.org/10.1016/j.ajic.2007.04.284. Retrieved November 18, 2019 from: https://www.sciencedirect.com/science/article/pii/S0196655307005949

16. Zhu, Jintuo, "Respiratory Flow Characterization of Workers in Healthcare Environment" (2018). Graduate Theses, Dissertations, and Problem Reports. 7287. Retrieved November 3, 2019 from: https://researchrepository.wvu.edu/etd/7287

17. TSI Inc. TSI SERIES 4000/4100 HIGH PERFORMANCE LINEAR OEM MASS FLOWMETER Design Guide. Feb 2016. Retrieved November 14, 2019 from: https://www.tsi.com/home/ PDF: https://www.tsi.com/getmedia/53b953c3-efb4-4ee9-81bc0e43b4626254/1980430-4000-4100-Design-Guide-web?ext=.pdf

18. TSI Inc. AirflowTM PVM100 Micromanometer Specifications Sheet. 2007. Retrieved November 14, 2019 from: https://www.tsi.com/discontinued-products/airflow-instrumentsmicromanometer-pvm100/\#resources

19. Berndtsson G, et al. 2002. "Peak Inhalation Air Flow During an Agility Test Performed by the U.S. Marine Corps". Journal of the International Society for Respiratory Protection, Vol. 21. Spring/Summer 2004. Retrieved November 10, 2019 from: http://www.sea.com.au/docs_menu/docs/pap_berndtsson_05.pdf

20. Sundstrom Safety Inc. 2019. SR 510 Particulate filter Product Leaflet. Retrieved November 10, 2019 from: https://www.srsafety.com/us/products/sr-510-particulate-filter-p100-he-h021321.html 


\section{Appendix}

Appendix A: PDL User Instructions

Appendix B: PDL Software Printouts 
Appendix A: PDL User Instructions 


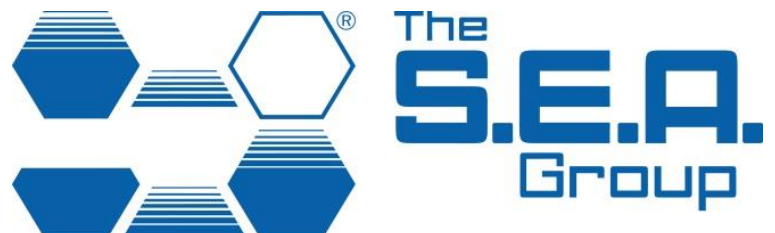 \\ theseagroup.com \\ Pressure data logger PDL User instructions}

100507-03 A

\section{Equipment description}

The Pressure data logger (PDL) is a portable battery-powered device used to collect real-time flow rate and mask pressure data for unassisted filtering respiratory protective devices (RPDs) in real use situations in the workplace, up to the duration of a full shift.

The test equipment consists of the following components:

- PDL unit with replaceable battery

- Precalibrated filter set

- Precalibrated exhalation valve assembly with sampling tube

- SR100 or SR200 respirator

- PDL software for use on Windows PCs 


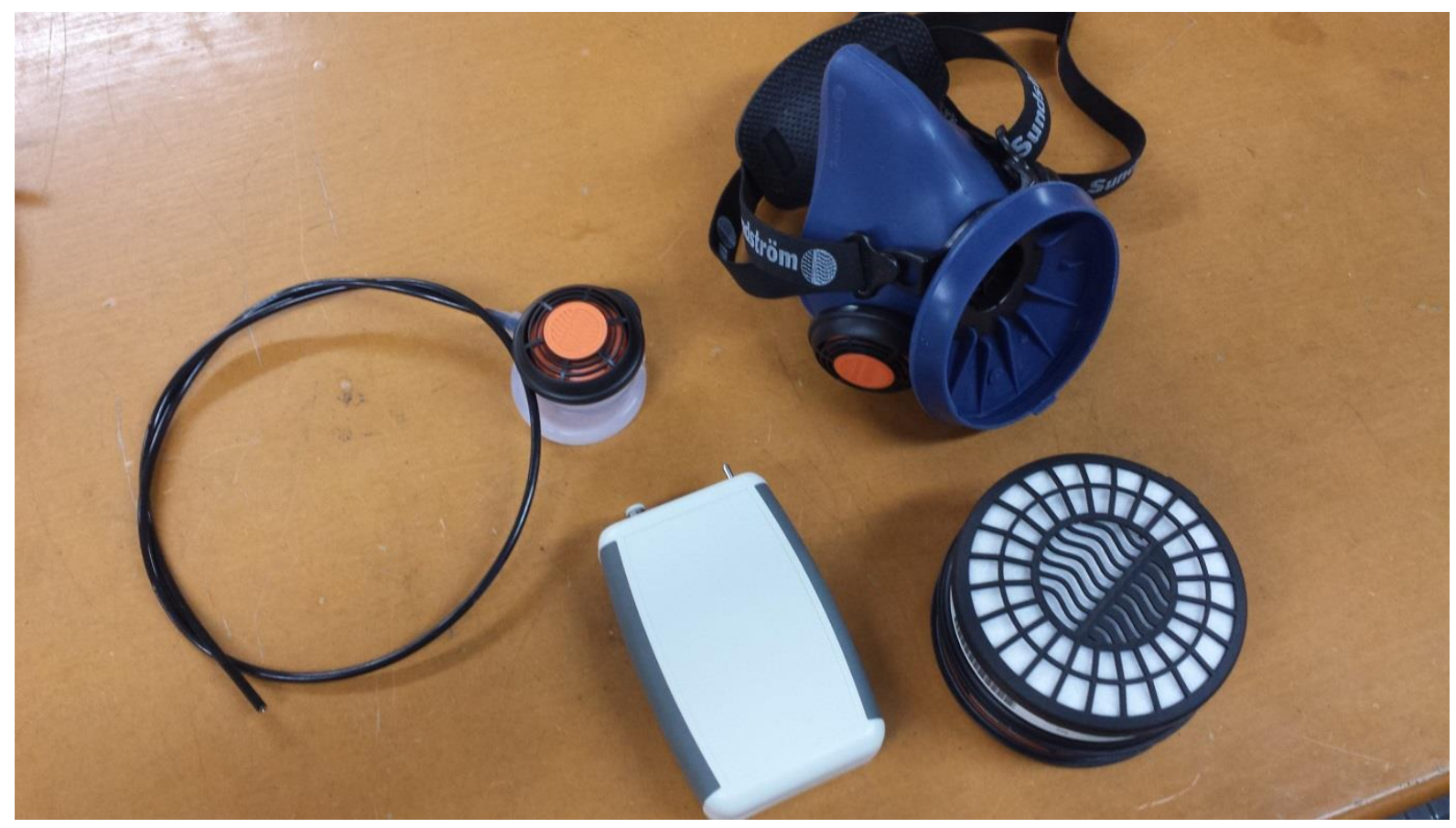

\section{Pressure data logger (PDL) unit}

The PDL is a small belt- or pocket-mounted unit powered by a $9 \mathrm{~V}$ battery. It measures mask pressure in real time when the pressure port is connected to the respirator breathing zone via a flexible tube.

The unit will operate continuously for at least a full shift on a single battery.

\section{Precalibrated filter set}

Each filter set consists of ABE1 gas filter, P3 particulate filter or a combination, plus a prefilter. The calibrated sets are used by the PDL to measure the flow rate during the inhalation phase.

Each filter set is marked with a serial number and two filter parameters (or calibration constants), "Aneg" and "Bneg". During the inhalation phase, the PDL logs the pressure drop across the filters. The calibration values are used to convert the pressure drop to inhalation flow rate.

Each filter set should be used for a single shift. After use, the filter set should be repacked in the resealable bag supplied and returned to S.E.A.

Important: Do not disassemble the filter sets, or remove or replace prefilters. If the filters are tampered with or damaged, the filter parameters may no longer be valid.

Note: If high measurement accuracy is not required it is acceptable to use one standard set of filter parameters for all tests, thus simplifying the process. 


\section{Precalibrated exhalation valve}

Users are supplied with a precalibrated exhalation valve assembly for each mask, with a pressure sampling tube connected to it. The calibrated exhalation valves are used by the PDL to measure the flow rate during the exhalation phase.

Each exhalation valve set is marked with a serial number and two filter parameters, "Apos" and "Bpos". During the exhalation phase, the PDL logs the pressure drop across the exhalation valve. The calibration values are used to convert the pressure drop to exhalation flow rate.

Important: Do not disassemble or tamper with the calibrated exhalation valve set as it may invalidate the filter parameters.

Note: The exhalation valve has lower air resistance and less predictable air/flow characteristic than the filters, therefore the accuracy of exhalation flow measurement will be less than inhalation, especially at lower flow rates.

\section{SR100 and SR200 respirators}

Any Sündstrom SR100 half facepiece or SR200 full facepiece respirator may be used for the test, provided that they are properly maintained and in good working order.

WARNING! The PDL and flexible tube must always be connected to the respirator during use. If not, the pressure sampling port will provide a direct leakage path to the ambient air, with resulting loss of breathing protection.

\section{Operation functions}

To replace the PDL battery

Before using in a workplace test, a new battery should be installed.

1. Remove the battery cover on the rear of the PDL.

2. Remove and disconnect the battery.

3. Connect a new $9 \mathrm{~V}$ battery, insert the battery and replace the battery cover.

Note. Do not leave the battery in the PDL unit as it may leak and cause damage.

To turn on the PDL

Before logging for a shift, ensure a new battery is fitted.

1. Press and hold READ and WRITE buttons (LED steady green) for about 5 seconds.

2. Release buttons. After 3 seconds the LED flashes orange.

The PDL is ready for use.

If logging has not been started within about 5 minutes of powering up, the unit will turn itself OFF. To restart, repeat the power-up process. 
To start logging with the PDL

With the PDL powered up:

1. Press and release the WRITE button. LED short-blinks red. The PDL is logging.

The PDL can log for at least an 8 hour shift.

Important! DO NOT TURN OFF the PDL at any time during logging, even while resting or when the respirator is not being worn.

\section{To turn off the PDL}

To turn off the PDL:

1. Press and release the READ and WRITE buttons. The LED stops blinking.

The logged data will remain in storage for future downloading. Even with the battery removed the data will remain stored.

\section{Preparation for use}

1. Ensure the wearer has been fit-tested for the type of respirator to be worn.

2. Ensure the PDL has a new battery fitted. If not, replace the battery.

3. Ensure the respirator is clean and sanitised, and is fully functional.

4. Fit the precalibrated exhalation valve assembly to the respirator as follows:

a. Remove one exhalation valve cover and exhalation valve from the respirator; put these items aside for refitting after the test.




b. Fit the silicone adapter of the precalibrated exhalation valve set to the exhalation valve seat of the respirator. Ensure the silicone is properly seated all around.

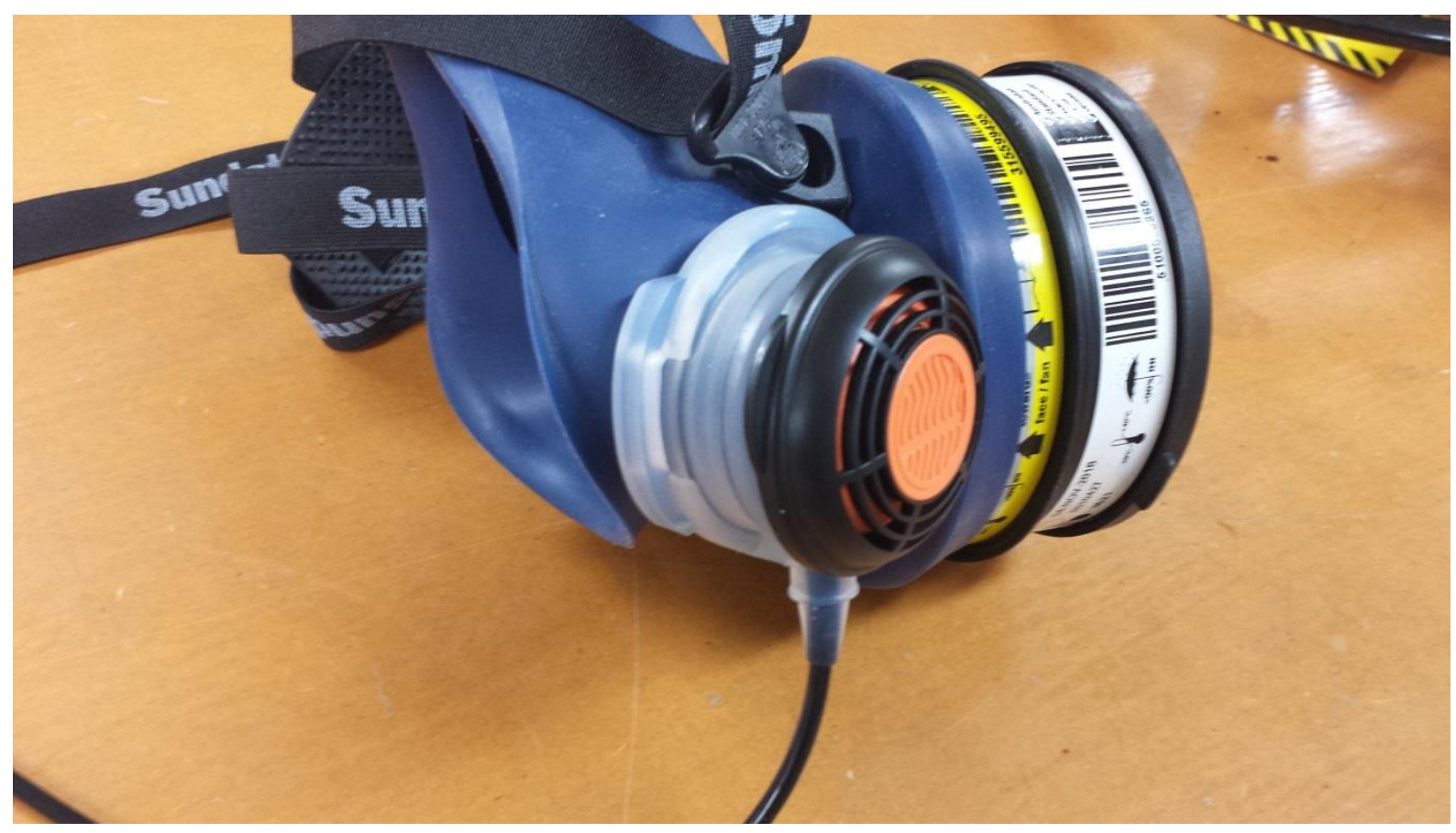

5. Connect the sampling tube to the PDL unit, and check that the connections are secure.

6. Fill out the test sheet.

\section{Operation of the PDL}

Starting the test

1. Turn on the PDL unit.

2. Don the respirator, attach the PDL unit to the wearer, and position the sampling tube to minimise the risk of snagging, kinking or crushing.

3. Start logging of the PDL.

4. Record the starting time (to the nearest minute) on the test sheet.

\section{Performing the test}

The wearer should proceed with the work tasks as per the normal routine.

The wearer may take rest breaks as per the normal routine. The PDL should be left running at all times, even when the respirator is not being worn.

Any special conditions encountered, or other observations, may be recorded on the test sheet.

\section{Stopping the test}

1. Turn off the PDL.

2. Doff the respirator. 
3. Record the stopping time (approximate only) on the test sheet.

\section{PDL software}

The PDL software, when installed on a Windows PC, allows the user to:

- download log files from the PDL unit, and view and save them

- open and view saved log files

- view charts of measured pressure for the whole log duration

- view pressure or flow rate for any selected time interval

- interpret a range of information from the logs, including:

○ instantaneous flow rates

○ minute volumes for a selected interval

○ air volumes that occurred within settable flow rate limits

○ work of breathing

- save data logs as Comma Separated Value (csv) files

Installation of the software entails:

1. Installation of the USB driver

2. Installation of the PDL software

\section{To install the USB driver}

The USB driver creates a virtual COM (serial) port using a USB port on the computer.

The installation executable files for the USB driver are supplied with the PDL.

To install the USB driver:

1. Double-click on:

CP210xVCPInstaller_x64.exe (64 bit computers)

or

CP210xVCPInstaller_x86.exe (32 bit computers)

2. Accept any operating system permissions to run the software. The installer window will appear: 


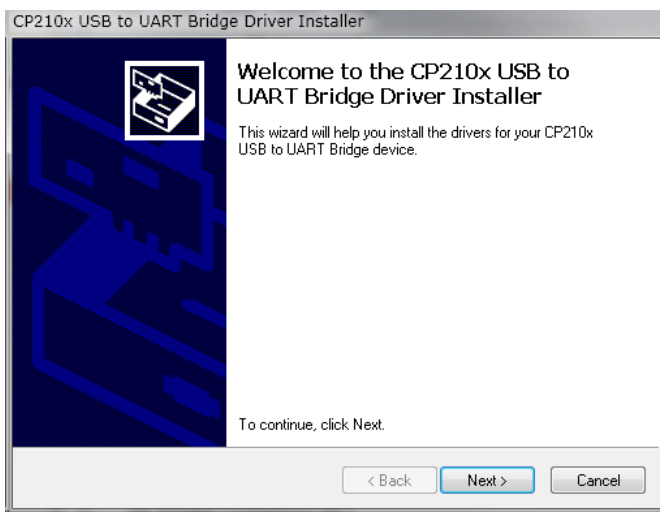

3. Click "Next."

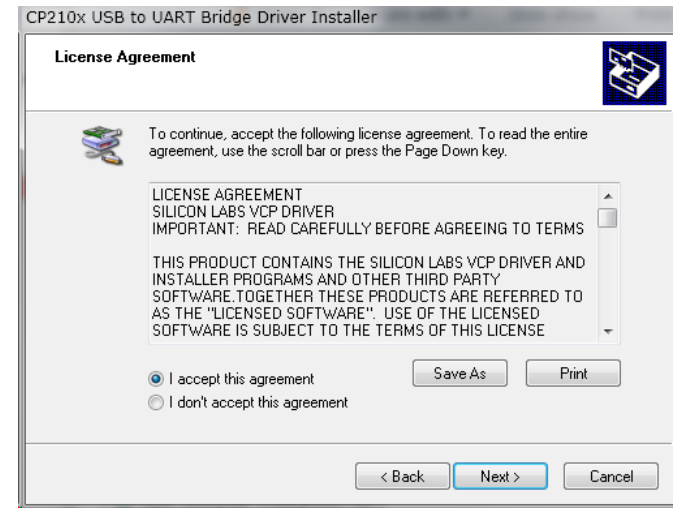

4. Accept the licence agreement and click "Next." The driver will install:

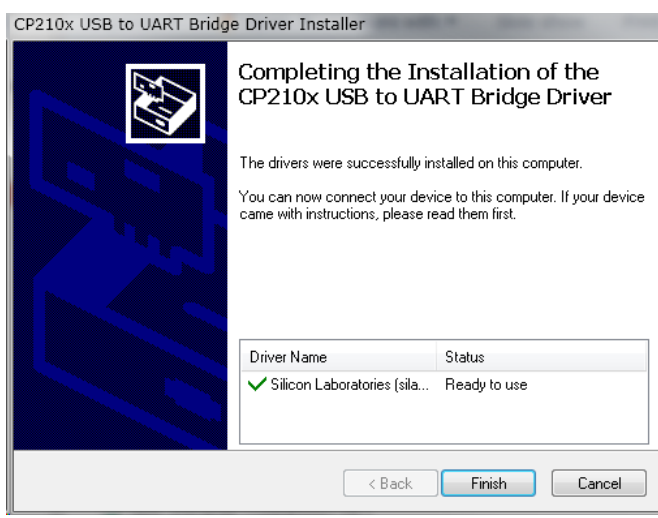

5. Click "Finish."

Silicon Labs CP210x USB to UART Bridge (COM3) $\triangleleft x$ Device driver software installed successfully.

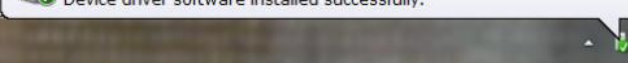

6. With a USB cable connect a USB port on the computer to the USB port on the PDL unit.

7. Check that the driver is installed. Go to Control Panel $>$ Hardware and Sound $>$ Device Manager. Open "Ports (COM \& LPT)". If installed correctly the COM port will appear. Note that this device appears on the list only whilst the PDL is connected to the computer. 


\begin{tabular}{|l|l|l|}
\hline Device Manager \\
\hline File Action View Help \\
Disk drives \\
Display adapters \\
DVD/CD-ROM drives \\
Human Interface Devices \\
KDE ATA/ATAPI controllers \\
Keyboards \\
Mice and other pointing devices \\
Monitors \\
Network adapters \\
Nortable Devices \\
Ports (COM \& LPT) \\
Port Silicon Labs CP210x USB to UART Bridge (COM3) \\
P Processors \\
Sound, video and game controllers \\
System devices \\
Universal Serial Bus controllers \\
\hline
\end{tabular}

8. Take note of the COM port number. In this example it is COM3.

\section{To install the PDL software (Windows PC only)}

The installation files are supplied with the PDL.

1. For a new installation double-click on:

\section{PressureLoggerV013-Installer.zip}

Alternatively, to upgrade an existing installation to a new version (currently v13) doubleclick on:

\section{PressureLoggerV013-InstallerNoRuntime.zip}

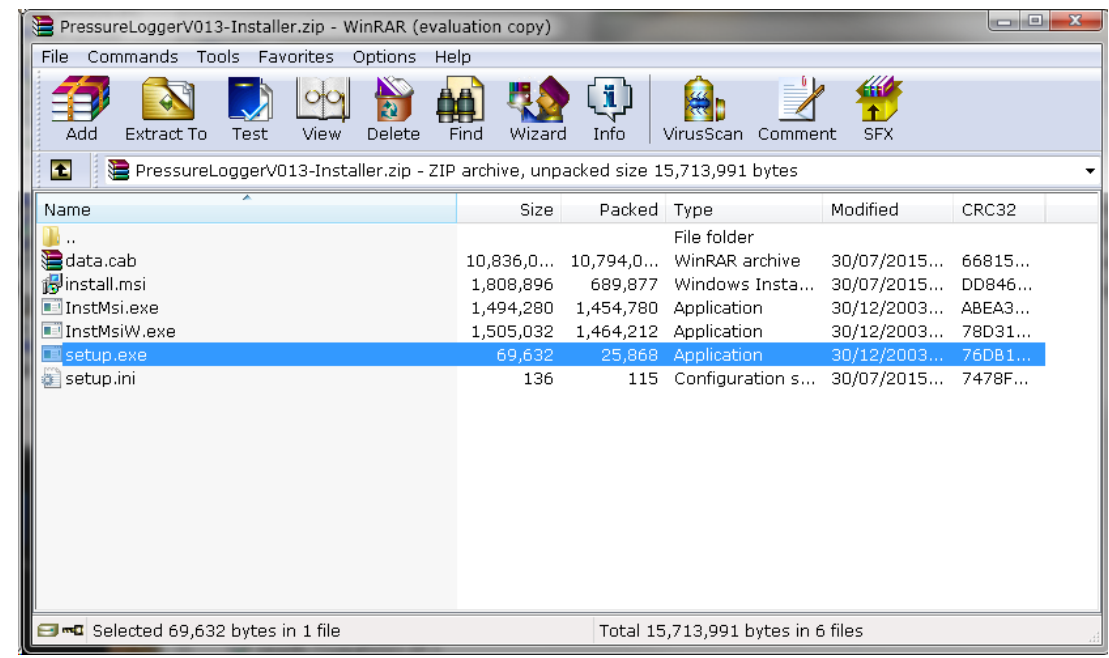

2. Double-click on setup.exe. If setup does not initiate, extract the zipped files to a storage location and run setup.exe from there. The installer window will appear: 


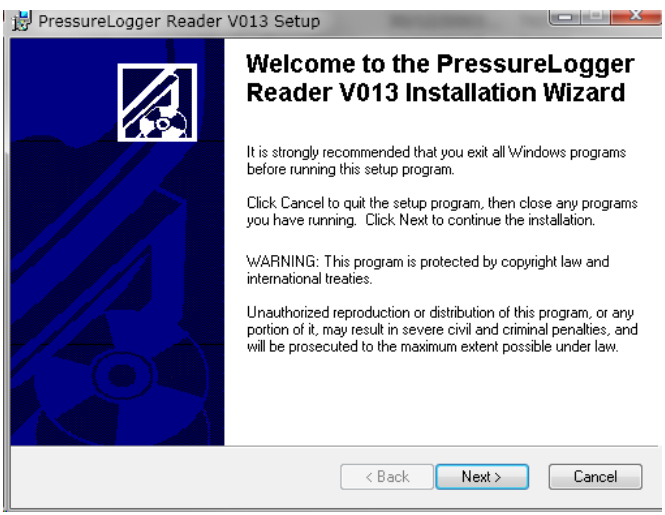

3. Click "Next." The Destination Folder dialog will appear:

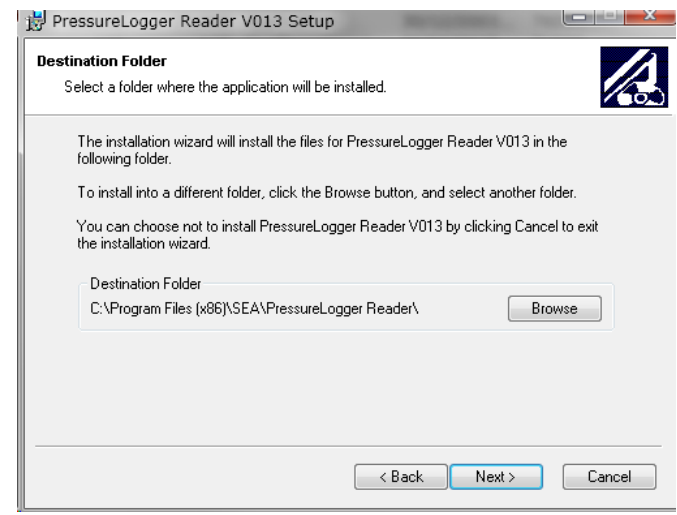

4. Select a new location or click "Next" to accept the default location. The Ready to Install dialog will appear:

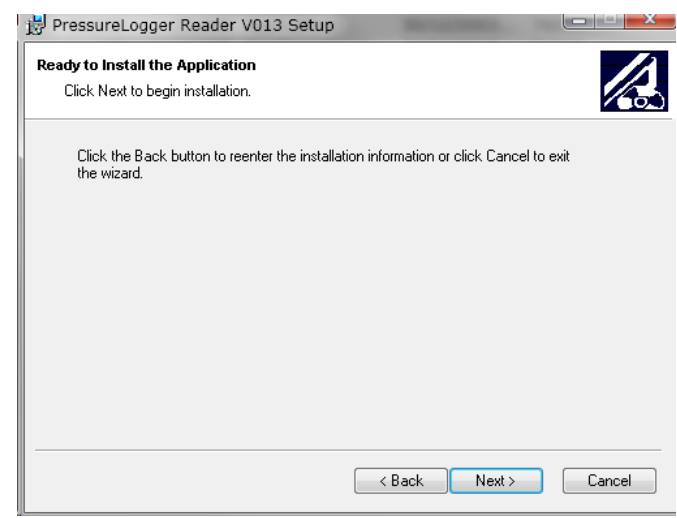

5. Click "Next." The installation will commence: 

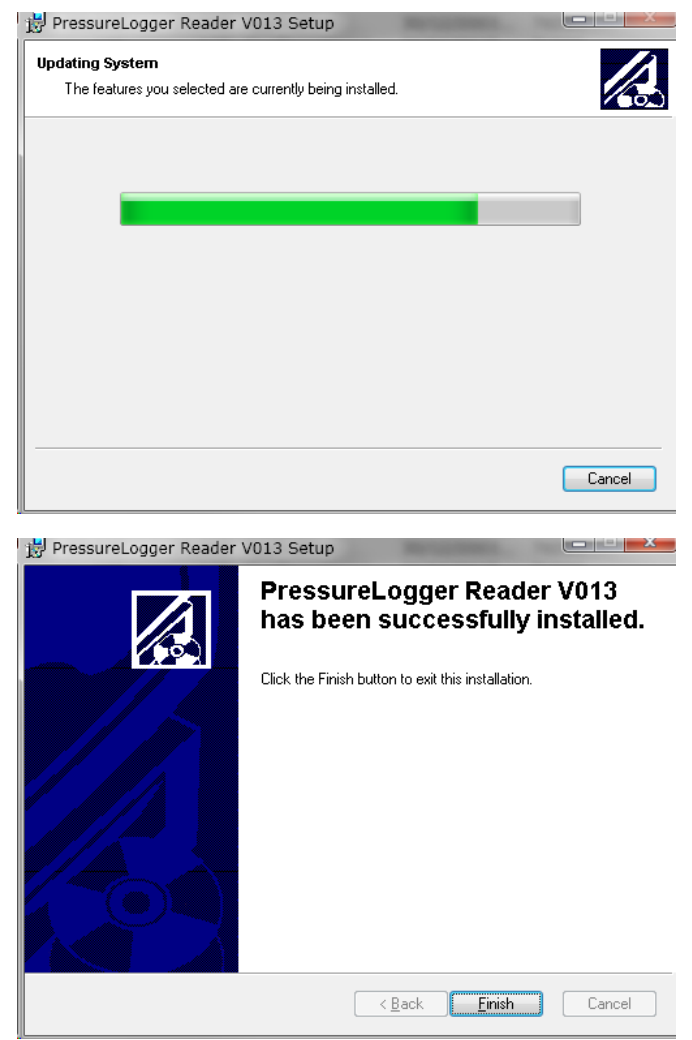

6. When the installation is complete, click "Finish."

\section{Using the PDL software}

To launch the PDL software

To launch the PDL software select Start > Programs > Pressure Logger Reader, or double-click the desktop icon. The software window will appear:

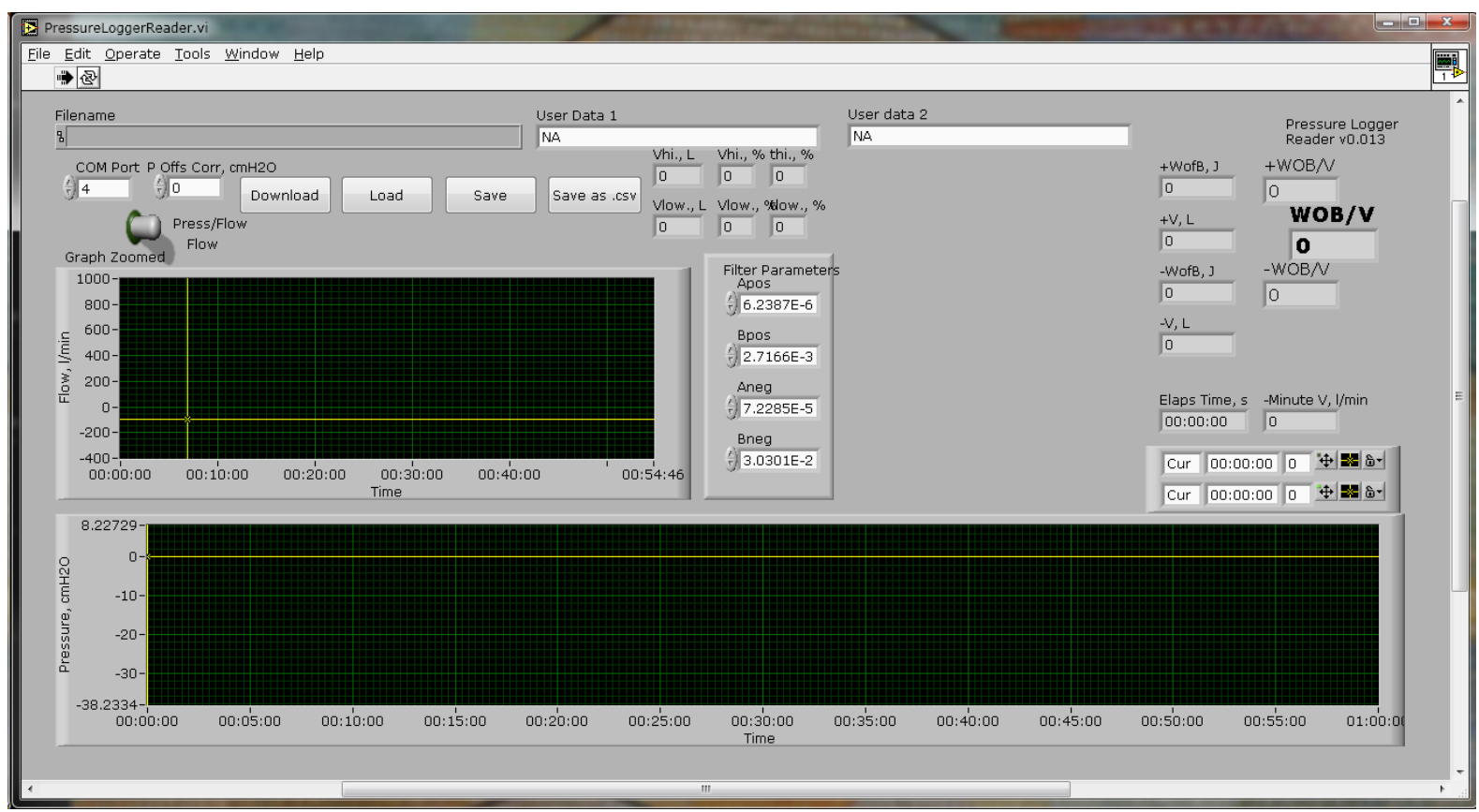




\section{To connect the PDL unit to the PC}

1. Enter the correct COM port number for the virtual COM port.

2. Connect the PDL unit to the PC using a suitable USB cable.

To download a data log from the PDL unit to the PC

The PDL software should be pre-installed on a PC.

1. Connect the PDL to a USB port on the PC

2. Check the com port which appears (the data logger creates a virtual serial port when connected to a USB port). Do this at: Control Panel->Hardware and Sound->Device Manager under Ports (COM \& LPT) section.

3. Run the PDL software.

4. Select the COM port to be used:

\section{Com Port}

3

5.

6. Click DOWNLOAD. The dialog "Please connect datalogger" will appear.

7. Turn on the PDL.

8. Click OK on the "Please connect datalogger" dialog. The software is now ready for download.

9. Press READ button on PDL. Downloading will commence. While downloading, a progress indicator will appear. Downloading may take up to 10 minutes, depending on the duration of the test. After all data is downloaded the PDL will switch itself OFF. The log now appears in the analyser window, but it is not yet saved to disk.

10. Enter the filter parameters that are marked on the filters and facepiece that were used to generate the data that has been downloaded. "Apos" and "Bpos" are for the exhalation valves (positive pressure); "Aneg" and "Bneg" are for the filter (negative pressure). 


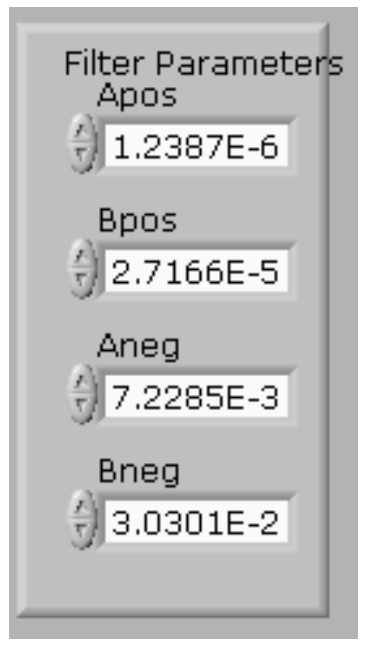

11. To apply the new parameters to the displayed data, refresh the display windows by toggling the "Press/Flow" switch.

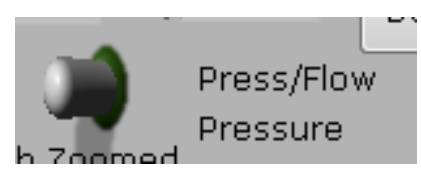

\section{To save a data log}

To save a file to the PC:

1. Click SAVE, which opens a conventional "save" dialog. Select a suitable location to save. Enter the desired filename and save.

\section{Save to a .csv file}

When saving to .csv (Comma Separated Value) file, the logged pressure and flow rate data points are saved, only for the time interval selected between the cursors in the main window. The sampling rate is 50 samples per second.

To save to a .csv file:

1. Select the desired time interval using the cursors in the main window

2. Click "Save as .csv"

3. Select a file location and file name as appropriate, and click "save".

Note: Selecting a large time interval will result in a very large file size.

\section{To open a saved data log file}

1. With the PDL software open, click the "Load" button (or click File > Open): 


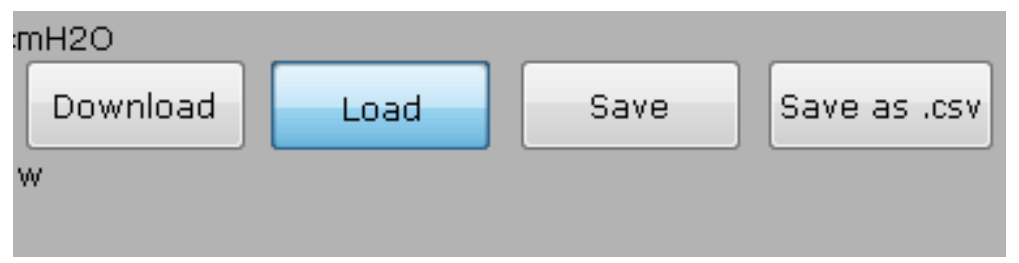

2. A windows "file open" dialog will appear. Browse and select the desired file, and click "open." The file data will appear in the software window.

\section{PDL software features}

The figure below shows the PDL software window. The various functions are identified and described in the text that follows.

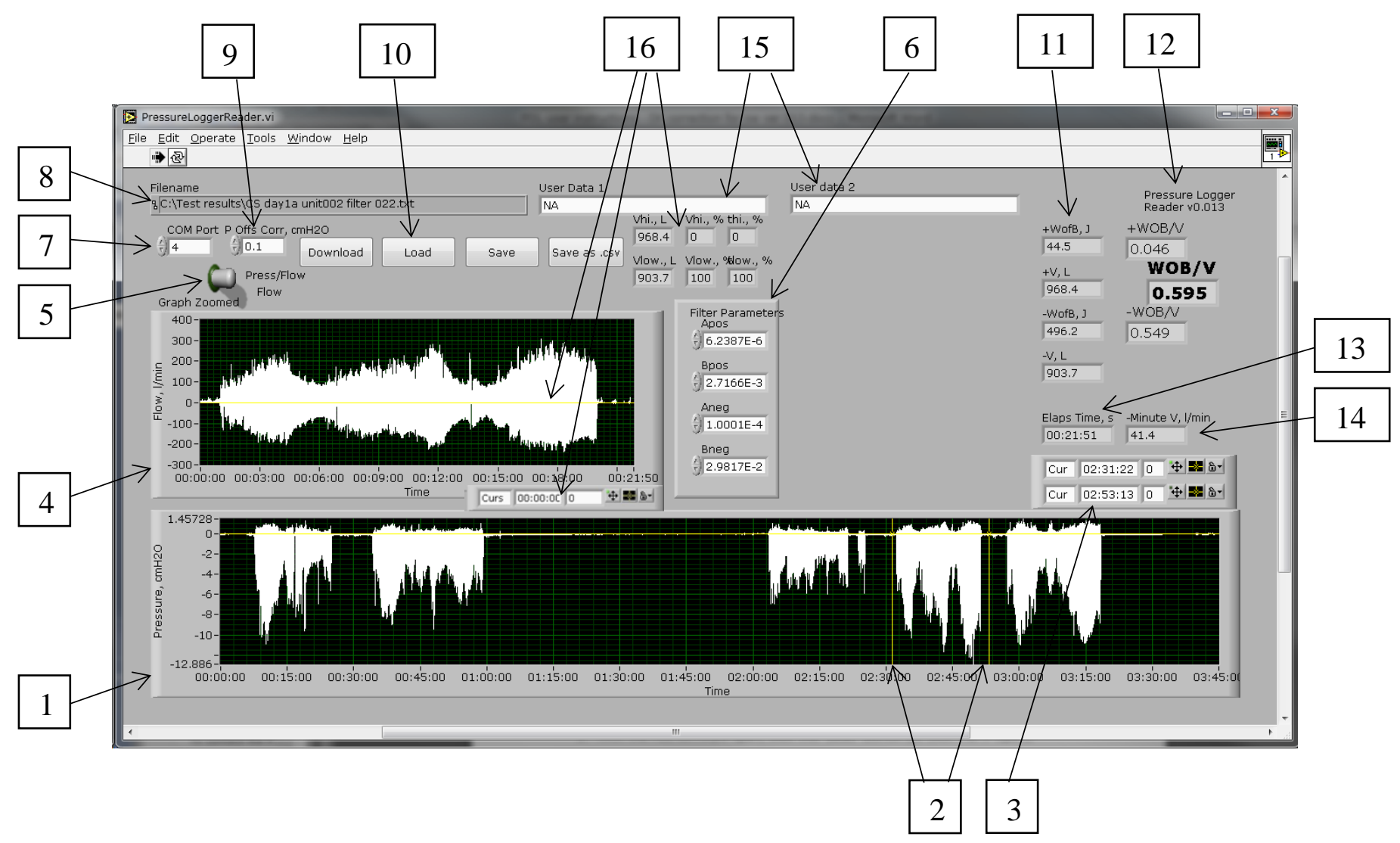

1. Main window - shows the entire pressure log. Displays Pressure $\left(\mathrm{cm} \mathrm{H}_{2} \mathrm{O}\right)$ vs Time (hh:mm:ss). In this example the total duration is $3 \mathrm{~h} 45 \mathrm{~m}$.

Note: It is apparent that the negative (inhalation) side has significantly larger magnitude than the positive (exhalation) side; this is because the inhalation resistance is higher than the exhalation resistance.

2. Selection cursors - click and drag the cursors to select data range for detailed analysis.

3. Cursor timestamps - show the exact cursor positions (hh:mm:ss). You can enter times here for precise positioning of the cursors. 
4. Detail window - displays the data range as selected by the cursors in the main window (1). Displays Pressure ( $\mathrm{cm} \mathrm{H}_{2} \mathrm{O}$ ) vs Time (hh:mm:ss), or Flow (1/min) vs time; use toggle switch (5) to choose.

5. Toggle switch - Toggles the detail window (4) between Pressure and Flow. When Flow is selected, the filter parameters (6) are applied to calculate the Flow from the Pressure.

Note: The toggle switch can be used to refresh the displayed data after settings have been changed.

6. Filter Parameters - Parameters as marked on the filters and exhalation valves that were used to generate the log. These values must be entered here manually, and are saved with the $\log$ file.

7. COM Port - Enter the COM port number to allow USB connection to the PDL unit.

8. File name - File name and location of current log file.

9. Pressure offset correction - enter value $\left(\mathrm{cm} \mathrm{H}_{2} \mathrm{O}\right)$ to apply an offset to the Pressure trace in the detail window (4). This function is used to correct for pressure drift in the logged data which would otherwise affect the accuracy of the derived data. The offset can be estimated by examining the trace when the respirator is not in use, but as close as possible to the data to be used. This value can be entered in the offset correction field, and the screen refreshed (by toggling the Flow/Pressure toggle switch).

\section{File management controls:}

a. Download - Download a log from the PDL unit

b. Load - Open a saved log file

c. Save $-\underline{\text { Save }}$ the current $\log$ data

d. Save as .csv - Export the current log as .csv (Comma Separated Value) file

11. Volumes and work of breathing - The software calculates the following data from the selected data displayed in the detail window (4):

a. $\quad+$ WofB, $\mathbf{J}$ - Work of breathing (Joules) for positive flow (exhalation) for the selected interval

b. $+\mathbf{V}, \mathbf{L}-$ Total exhaled volume (litres) for the selected interval

c. -WofB, J - Work of breathing (Joules) for negative flow (inhalation) for the selected interval

d. $-\mathbf{V}, \mathbf{L}-$ Total inhaled volume (litres) for the selected interval

e. $+\mathbf{W O B} / \mathbf{V}$ - Volume-averaged pressure $(\mathrm{kPa})$ for positive flow (exhalation) for the selected interval

f. $-\mathbf{W O B} / \mathbf{V}-$ Volume-averaged pressure $(\mathrm{kPa})$ for negative flow (inhalation) for the selected interval 
g. WOB/V - Total volume-averaged pressure $(\mathrm{kPa})$ (sum of exhalation and inhalation) for the selected interval

Note: The WoB/V values are equivalent to volume-averaged pressure defined in draft ISO 16900-12.

Note: Often there is a discrepancy between the exhaled and inhaled volumes; this is due to the lower accuracy of the measurement of exhalation flow rate. In case of discrepancy the inhalation flow rate should be given precedence.

\section{PDL software current version}

13. Elaps time, $\mathbf{s}$ - the time interval (seconds) of the selected interval shown in the detail window (4).

14. -Minute $\mathbf{V}(\mathbf{l} / \mathbf{m i n})$ - the minute volume ( $1 / \mathrm{min})$ averaged over the selected interval shown in the detail window (4).

15. User data - Two fields in which users may enter information about the log file.

16. Adjustable threshold and derived data - The horizontal yellow line on the detail window (4) is an adjustable threshold. Specific volume data can be derived from this. This feature is described in section Adjustable threshold.

\section{Adjustable threshold}

The horizontal yellow line on the detail window can be moved vertically, either by dragging and dropping or by entering a flow value in the field at the bottom of the window.

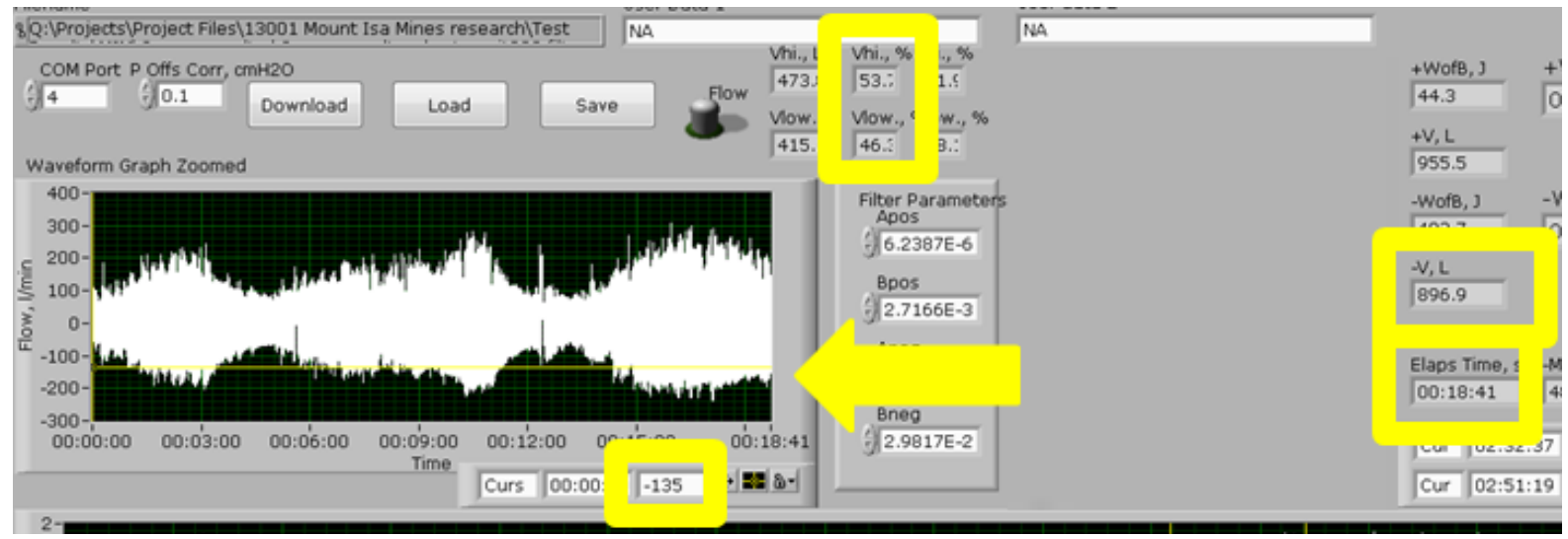

In the example above the threshold is set at $-1351 / \mathrm{min}$. The elapsed time for the selected data is $18 \mathrm{~m} \mathrm{41s.} \mathrm{The} \mathrm{total} \mathrm{inhaled} \mathrm{volume}(-\mathrm{V}, \mathrm{L})$ is 896.9 litres, and the minute volume is $48 \mathrm{l} / \mathrm{min}$.

Vlow \% indicates $46 \%$. This means that the air volume below the threshold line is $46 \%$ of the total inhaled volume. In other words, $46 \%$ of the total inhaled volume passed through the filter at a flow rate of $135 \mathrm{l} / \mathrm{min}$ or greater.

Vhi \% indicates the balance of the inhaled volume - i.e.: $(100-$ Vlow $) \%$. 
The figure above illustrates how the volumes are calculated. This example is for a single breath. The minute volume for this breath is 78.2 litres; PIFR is $2201 / \mathrm{min}$.

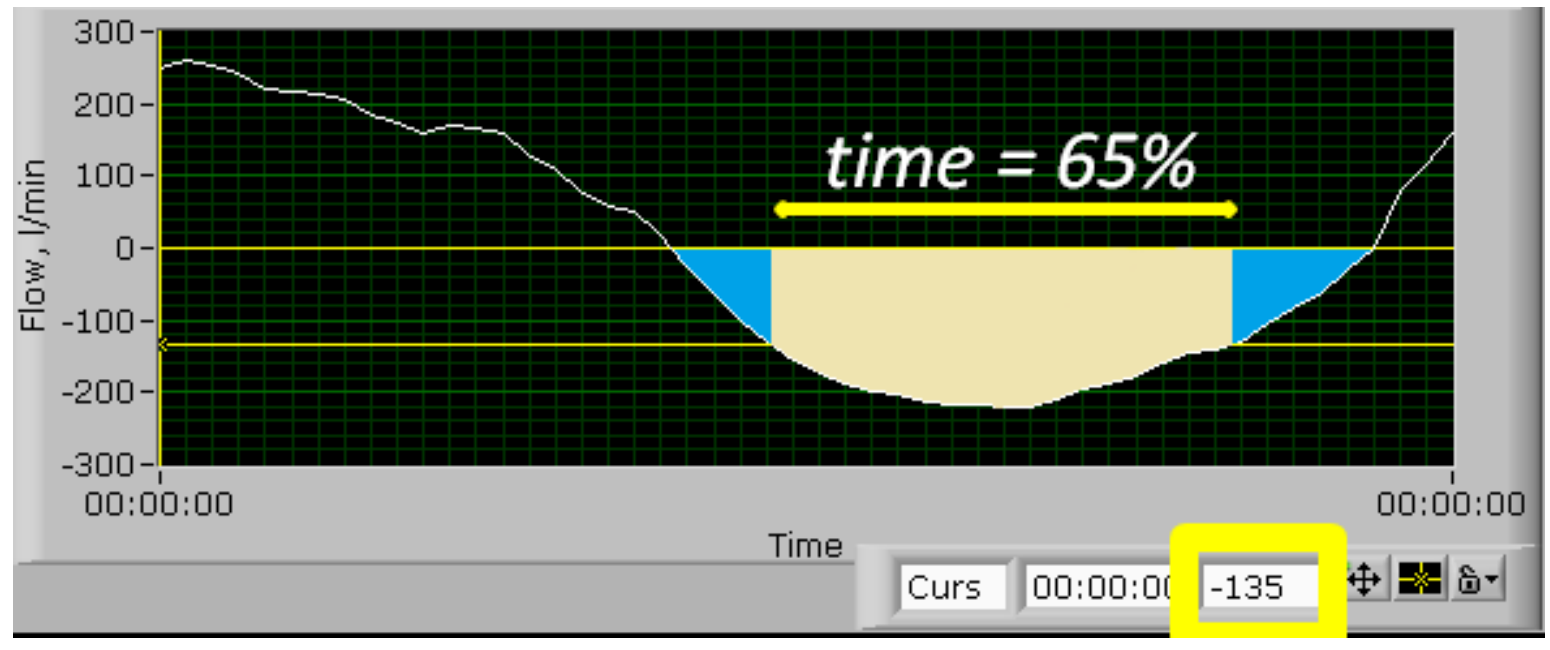

The volume of air that passed through the filter at 135 1/min or greater (representing $65 \%$ of the duration of the inhalation phase) is indicated by the yellow area. It represented $81 \%$ of the total volume of the breath.

Note: This feature is designed to be used on the inhalation side of the curve only. If the threshold is set to the positive (exhalation) side the Vhi and Vlow data become meaningless.

\section{Other PDL functions}

To generate a data stream

(Not required for normal operation.)

The PDL has a "data stream" mode, whereby, instead of logging, it outputs a stream of real-time data. This function is not required for normal testing.

1. Power up the PDL.

2. Connect the PDL to a reading device (PC or other) via the USB cable.

3. Press READ and WRITE buttons, then release READ button while holding WRITE button for 10 seconds.

A continuous stream of data will commence.

To stop the data stream, power down the PDL.

The data stream is the pressure data which is transmitted in ASCII HEX format (raw A2D data) where FFE (HEX max or DEC 4094) corresponds to $40 \mathrm{~cm} \mathrm{H}_{2} \mathrm{O}$ (inhalation) and 000 (HEX min or DEC 0) corresponds to $-7 \mathrm{~cm} \mathrm{H}_{2} \mathrm{O}$ (exhalation) followed by LFCR (HEX 0x0A, 0x0D).

\section{Appendix 1 - Filter characterisation}

Method for determining pressure/flow characteristic of filter 
The purpose of the method is to derive a pressure drop vs flow rate characteristic for the filter. When subsequently used with the PDL, the filter acts as a flow rate measuring device for inhalation air.

The desired accuracy of the resulting data should be considered in deciding whether to characterise each individual filter set to be used in trials. For maximum accuracy, each filter set used should be characterised individually. If lower accuracy is acceptable, it may be valid to use the constants from another identical filter set.

Because measurement of exhalation flow rate using the exhalation valves is inherently less accurate than inhalation flow measurement with the filter, it is generally acceptable to use a standard set of constants for all tests with the same type of respirator.

Note that the characterisation must be done for the filter in the configuration it will be used in trials - for example, prefilters should be fitted, etc. - and kept as a set thereafter.

\section{Filter characterisation method}

The general method for characterising the filter is as follows:

1. Set up the following configuration:

a. Fit the complete mask and filter to a dummy head, the mouth of which is connected to a variable flow rate suction device. A sampling port should be located in the breathing zone of the dummy head in order to measure pressure downstream of the filter. (Alternatively, the same can be achieved without a dummy head by connecting the outlet of the filter via an adaptor to the suction device; the sampling port should be downstream of the filter.)

b. Connect the sampling port to a pressure transducer which is connected in turn to a data acquisition system. The pressure transducer should be configured to measure the filter pressure relative to ambient pressure; this is equivalent to the pressure drop across the filter.

c. A flow meter should be inserted between the sampling port and the suction device.

2. Record the pressure at zero flow.

3. Start the vacuum device. Record the pressure and flow rate readings at a series of flow rates up to approximately $400-500 \mathrm{l} / \mathrm{min}$. All flow rate readings must be corrected to standard pressure and temperature of the flow meter.

4. Tabulate the flow/pressure data on a spreadsheet, plot the points on a graph, create a second-order polynomial best-fit curve and determine the formula. This is the flow/pressure characteristic of the filter. These calculations can be done easily with MS 
Excel or LabView software. S.E.A. provides a proforma Excel spreadsheet for this purpose.

5. The second order constant in the characteristic equation is constant "Aneg"; the first order constant is constant "Bneg".

The same method can be applied to determine the characteristic of the exhalation valves.

Note: The filter characteristic can be represented by a second order polynomial best-fit curve. This can be determined using only three data points. However it is recommended to use more data points to ensure high accuracy.

() Copyright The S.E.A. Group 2015 
Appendix B: PDL Software Printouts 


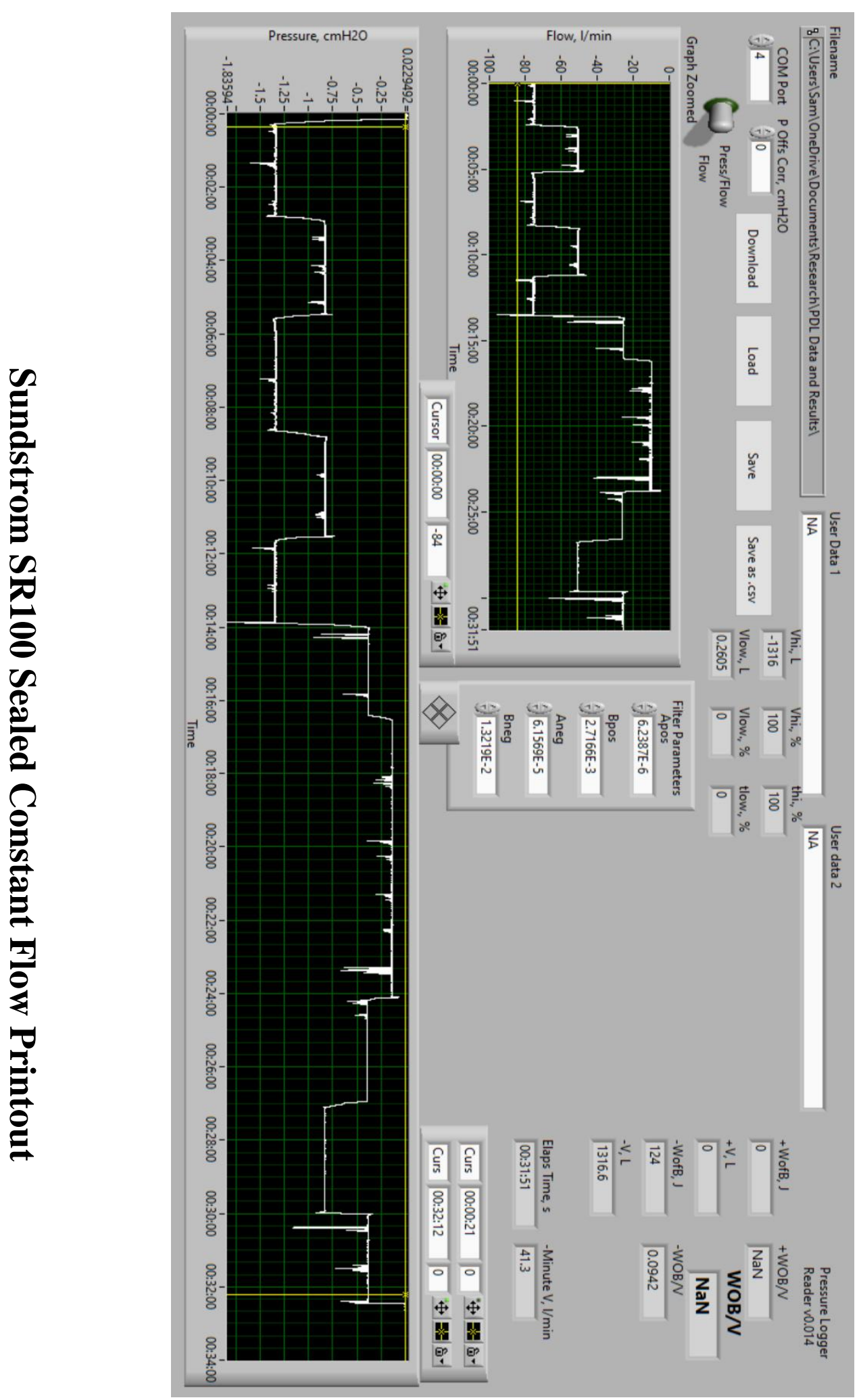




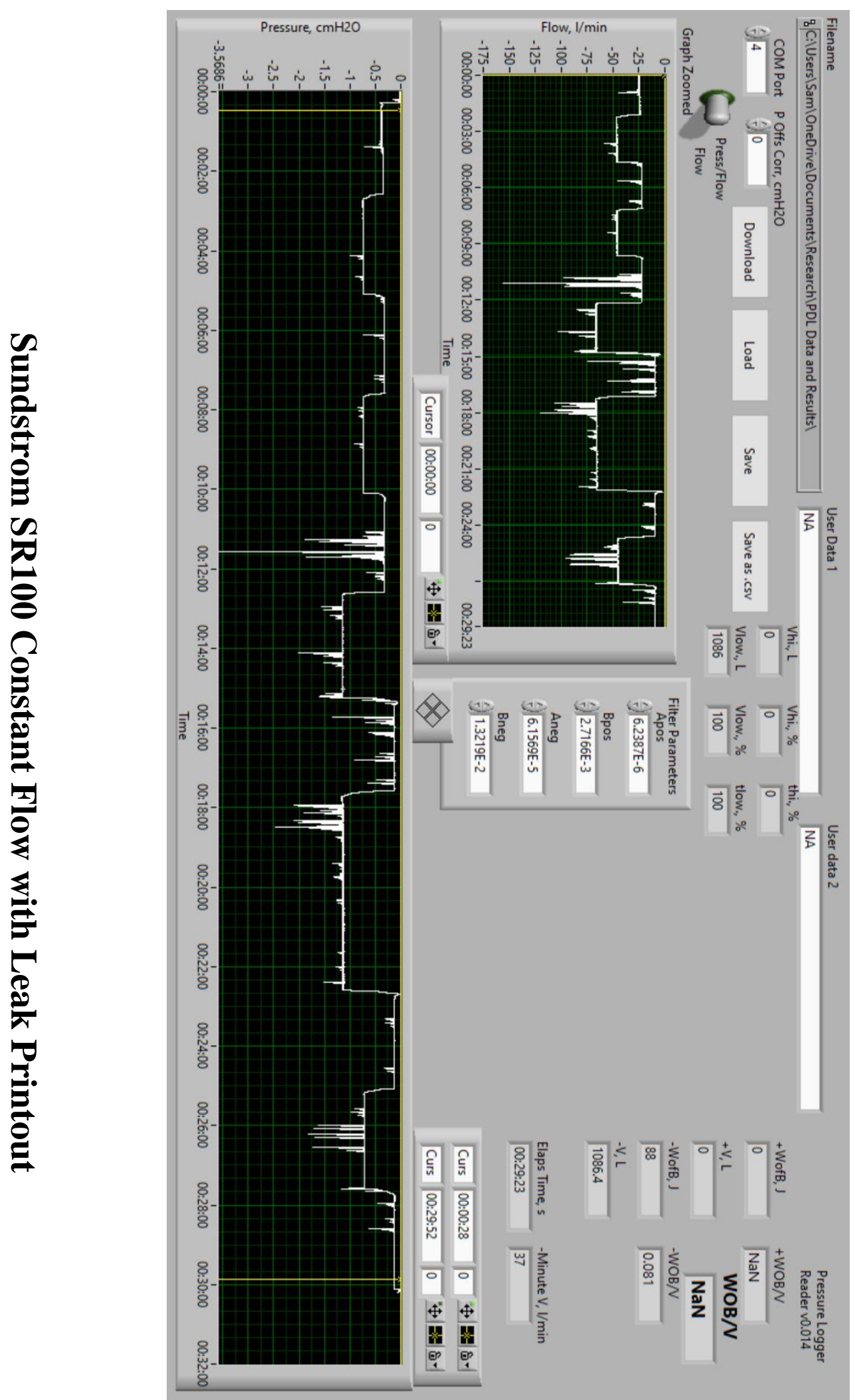



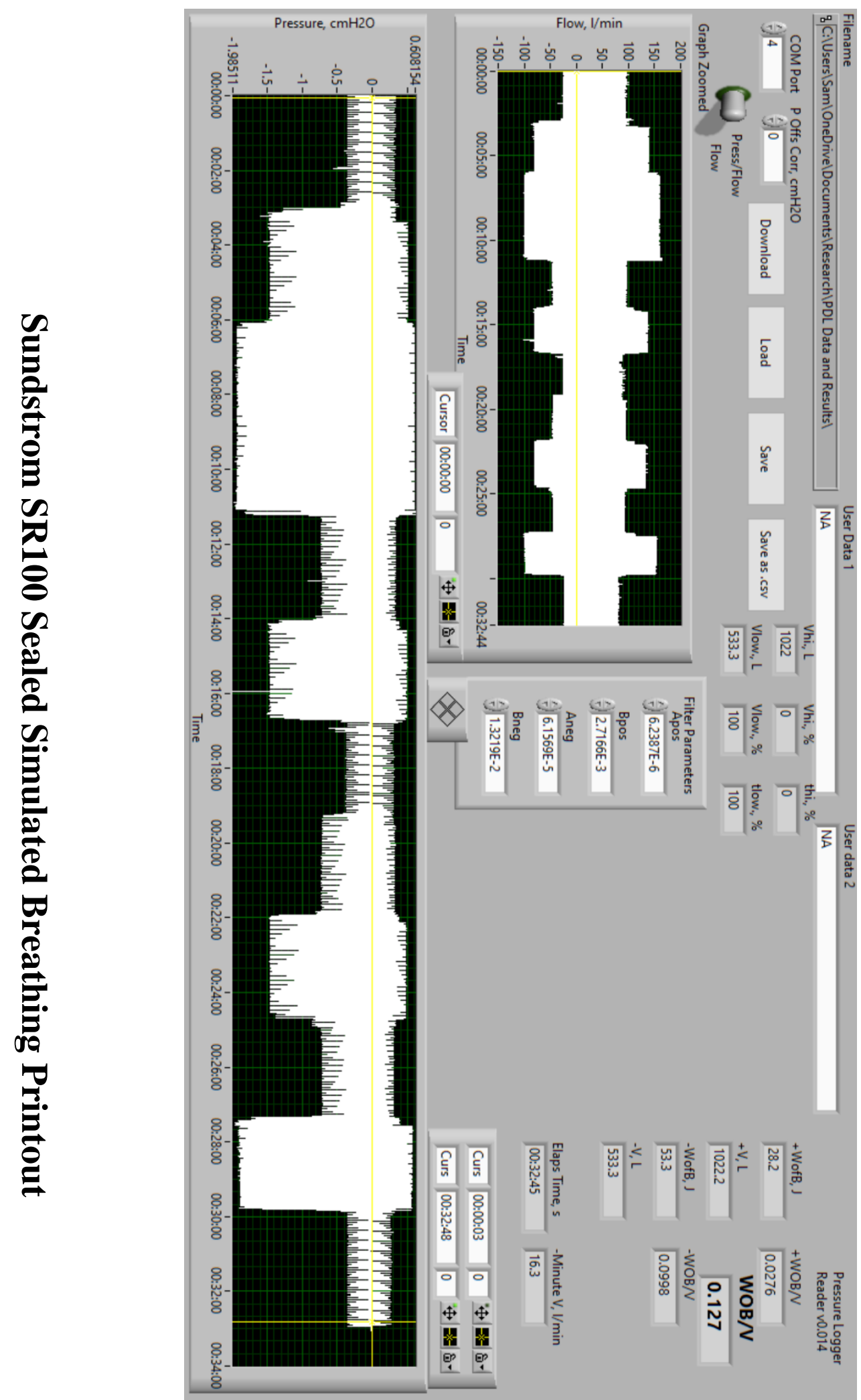

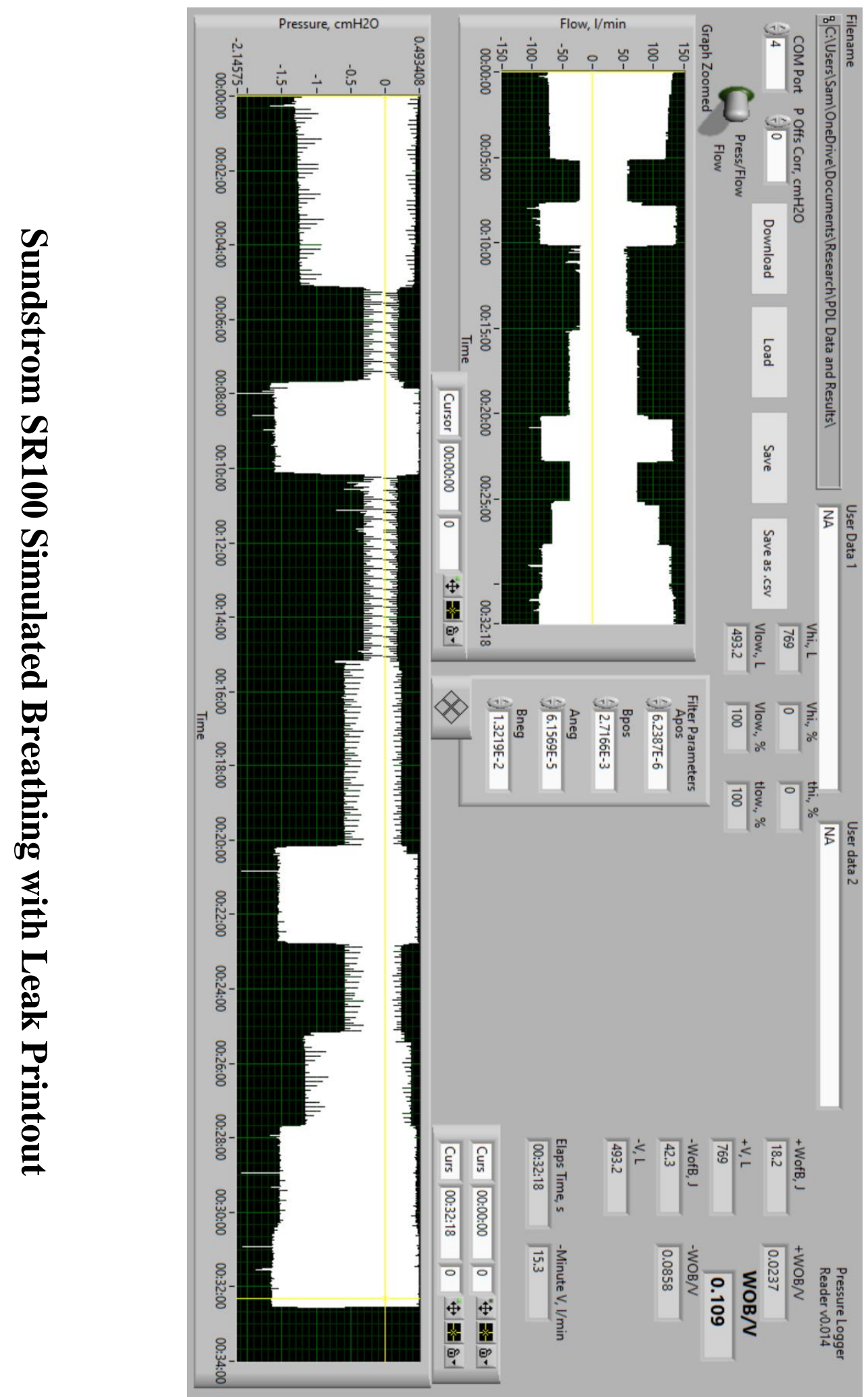


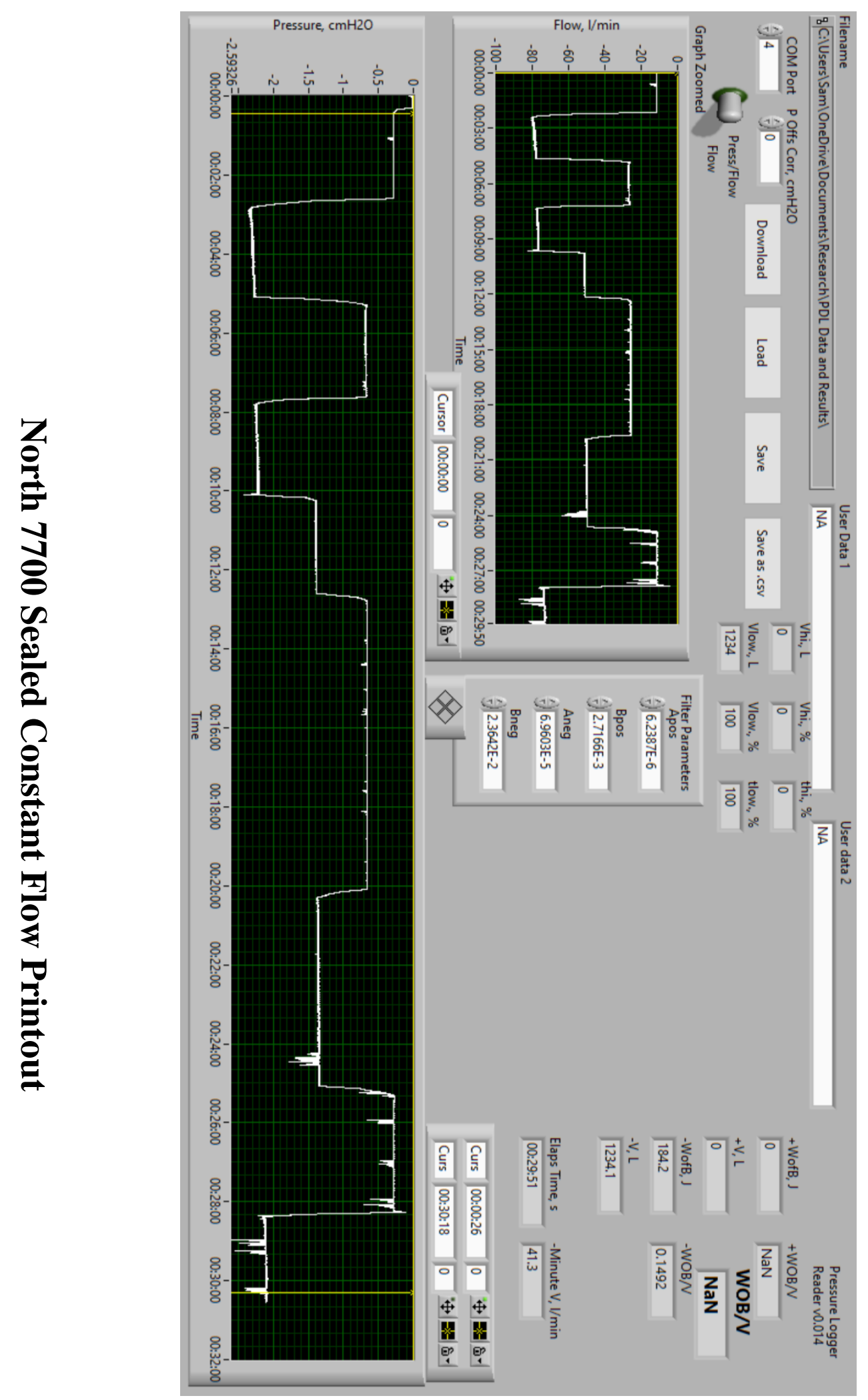




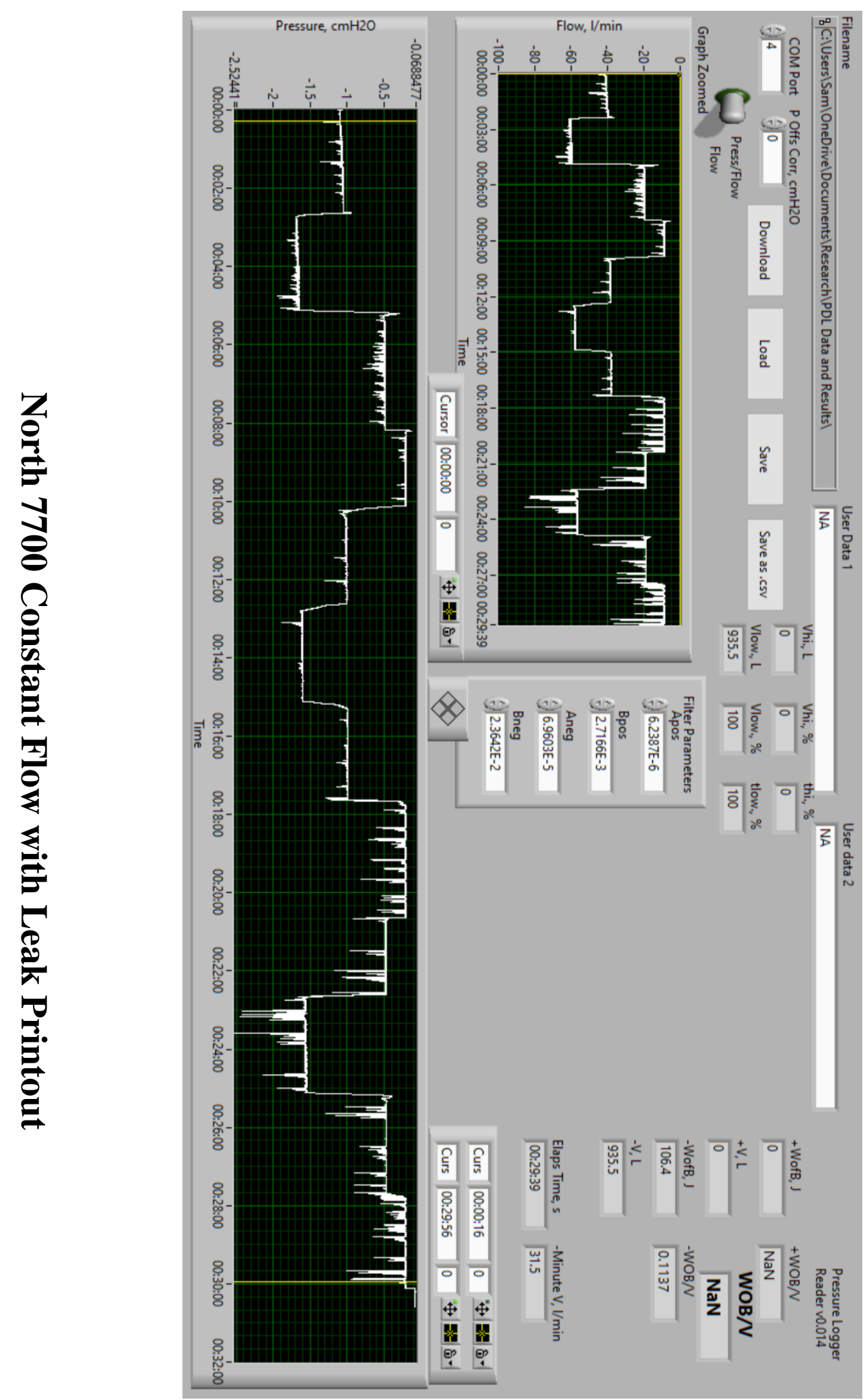




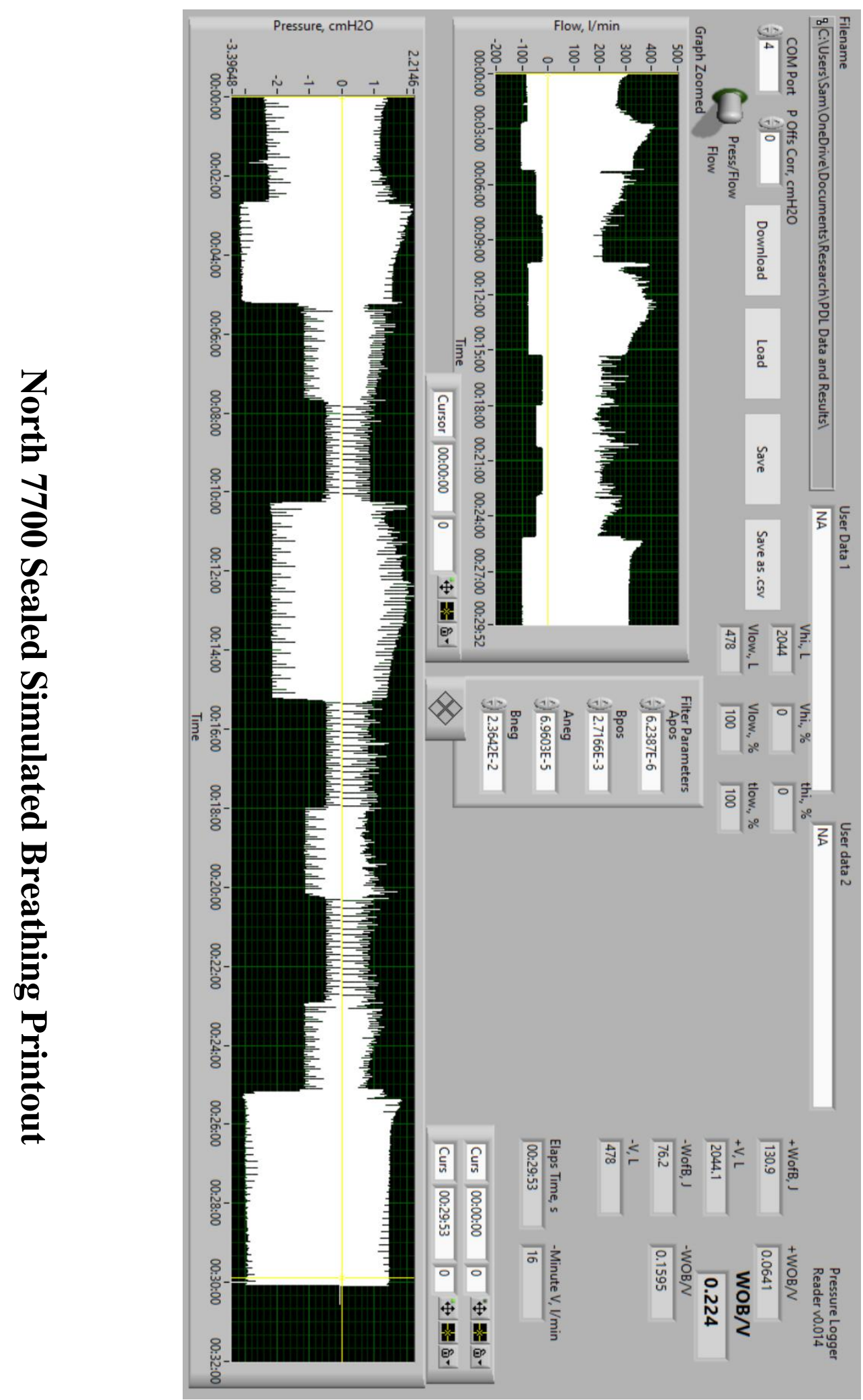




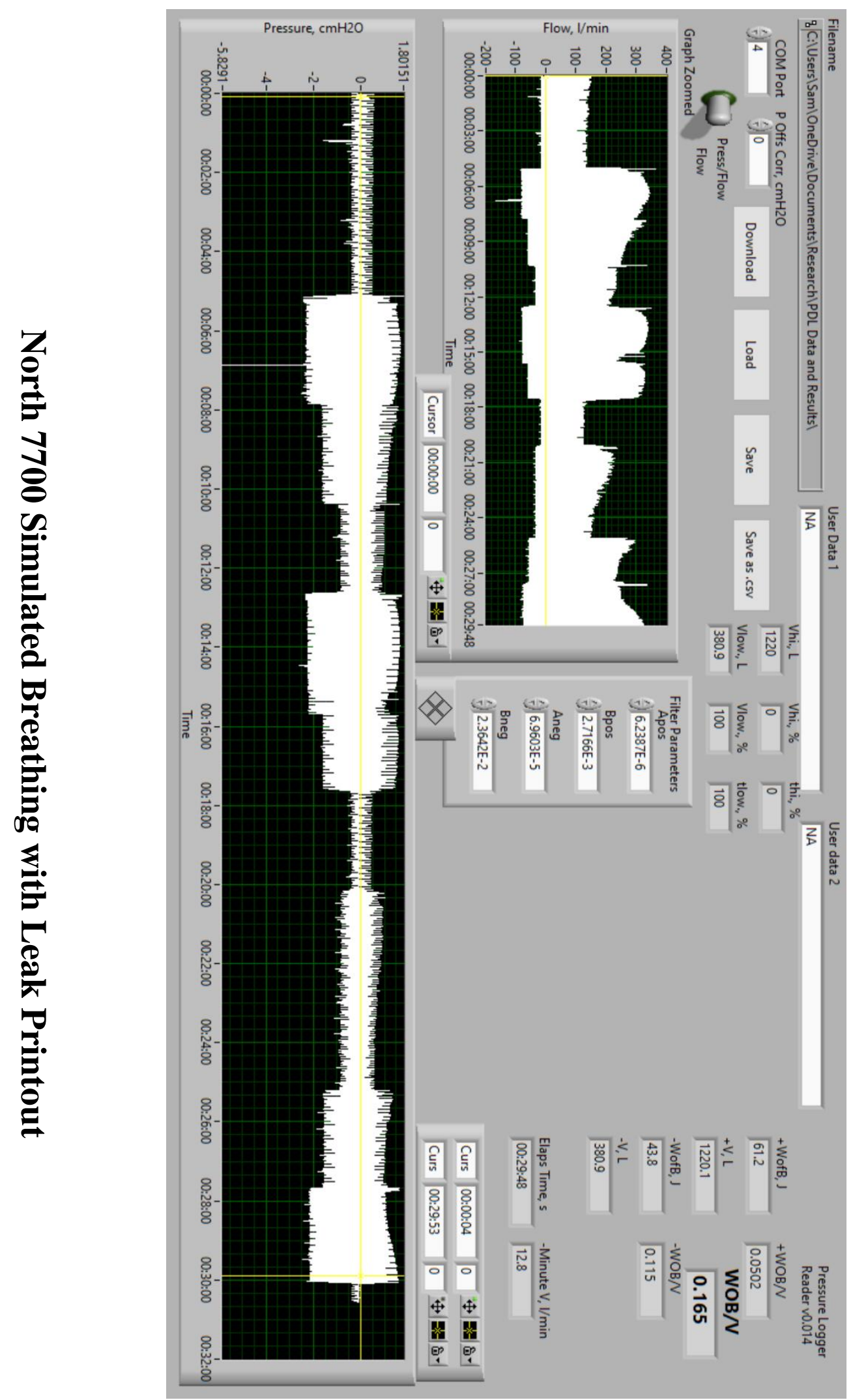

